\title{
PROTECCIÓN JURÍDICA DE LOS ADULTOS MAYORES EN CHILE*
}

\section{LEGAL PROTECTION OF OLDER ADULTS IN CHILE}

\author{
FABIOLA LATHROP ${ }^{* *}$
}

RESUMEN: Este artículo examina la situación jurídica de los adultos mayores en Chile y analiza un tipo de discriminación por edad: el maltrato contra las personas ancianas, en especial, la situación en los hogares e instituciones de larga estadía. Describe el concepto, los tipos y los factores de riesgo del abuso contra los adultos mayores, y propone algunas soluciones legales introducidas en varios países para protegerlos. Finalmente, se esbozan algunas conclusiones con el objeto de contribuir al incipiente debate chileno sobre la protección de las personas ancianas.

Palabras clave: adultos mayores, envejecimiento poblacional, discriminación por edad, maltrato, instituciones de larga estadía.

ABSTRACT: This article reviews the legal situation of older adults in Chile and analyses a type of age discrimination: the mistreatment against older people; specially, the situation in nursing homes and long-term care institutions. Describes the concept, types and risk factors of the abuse against older adults, and proposes some legal solutions that have been introduced in several countries to protect them. Finally, this article draws some conclusions to contribute to the incipient Chilean debate regarding protection older people.

Key words: older adults, population ageing, age discrimination; mistreatment, long-term care institutions.

"E se alla sua età le difetterà la competenza, presto affinerà le capacità con l'esperienza"

(La città vecchia, Fabrizio De Andrè)

\section{A MODO DE INTRODUCCIÓN}

Al contrario de lo que ocurre hoy, cuando demasiadas veces nuestros viejos sufren el desprecio de la sociedad y de sus propias familias, la ancianidad fue objeto de continua veneración en la antigüedad. Los ancianos eran considerados portadores de la más excelsa sabiduría y reserva de la memoria ancestral, al punto de poder afirmar que la vejez representaba el archivo histórico de la comunidad. Así, retrospectivamen-

\footnotetext{
* Este trabajo es parte de un Proyecto llevado a cabo con el Fondo de Ayuda a la Investigación de la Universidad Finis Terrae, del cual la autora es investigadora responsable.

** Licenciada en Ciencias Jurídicas y Sociales, Universidad de Chile. Doctora en Derecho, Universidad de Salamanca, España. Profesora de Derecho Civil, Universidad Finis Terrae. Dirección Postal: Avda. Pedro de Valdivia 1509, Providencia, Santiago de Chile. Correo electrónico: flathrop@uft.cl.
} 
te, puede afirmarse que las culturas primitivas constituyeron el "periodo de gloria" de los ancianos ${ }^{1}$.

La denominada "tercera edad" ha inspirado numerosas reflexiones filosóficas e importantes obras de la literatura ${ }^{2}$. Diversas disciplinas, como la sociología, la medicina y, por cierto, la gerontología, han abordado la problemática de la ancianidad en profundidad.

Sin ir más lejos, la bioética -o si se quiere, más modernamente, el bioderecho- ha analizado también ciertas situaciones de desprotección del anciano. En efecto, y como veremos a lo largo de este artículo, en muchas situaciones de pacientes institucionalizados, estos pierden autonomía en el ejercicio de ciertos derechos, de manera que decisiones que en principio son personalísimas, pasan a ser adoptadas por sus familias e, incluso, por funcionarios estatales que deben jerarquizar recursos públicos, situación que, como se ha señalado, puede desembocar en una "eutanasia social directa o indirecta"”.

En el ámbito jurídico, desde hace un par de décadas ha comenzado a surgir en el contexto internacional y comparado, la idea de la creación de un estatuto que otorgue un adecuado marco de protección a los adultos mayores. En este sentido, en Europa occidental -que suele servir de paradigma en estas y otras cuestiones de índole sociallas políticas se centraron, en los albores del siglo XX, en la mera asistencia económica y sanitaria de los adultos mayores; en los años ochenta, en cambio, comenzaron a desarrollarse directrices de mayor proyección construidas en torno a políticas de vivienda, como las viviendas-servicios dotadas de equipamiento asistencial; políticas de salud, que previeron asistencia especializada; y políticas asistenciales ${ }^{4}$, que han ido afianzándose progresivamente.

Con mayores pretensiones se sostiene que así como existe un Derecho de la Infancia y de la Adolescencia, debiera existir un Derecho de la Ancianidad ${ }^{5}$ e, incluso, Tribunales de la Ancianidad ${ }^{6}$, de forma que, al inicio y al final de la línea de la vida, el ser humano reciba una protección, acorde con sus necesidades y autonomía, que ponga fin al estado de indefensión que, desgraciadamente, buena parte de las veces sufren.

No obstante, lo cierto es que el interés que esta materia ha despertado en el ámbito jurídico es todavía incipiente. Realidad a la que, lamentablemente, nuestro país no escapa.

En efecto, el gran hito de la reforma previsional del 2008 -que beneficiará sin duda a un importante número de adultos mayores-, y la denuncia mediática de escabrosos casos de maltrato contra ancianos, nos demuestra que existe una preocupación por mejorar y visualizar las condiciones de vida de este sector y el estado de abandono y precariedad en que se encuentran muchos ancianos. Sin embargo, nuestro ordenamiento jurídico dista mucho de ese tan ansiado Derecho de la Ancianidad. Son muy pocas las normas legales que se refieren específicamente a los adultos mayores y, la gran mayoría

\footnotetext{
${ }^{1} \mathrm{Al}$ respecto, TREJO (2001) pp. 109-110.

2 A modo de ejemplo: CiCERÓn (2001); y Bobbio (1997).

3 ViVANCO (2003) p. 212. Para un tratamiento en mayor profundidad sobre esta temática, también OUTOMURO (2003).
} 
de las veces, la protección que ellas otorgan no alcanza el grado de especificidad que se requiere para que sea eficaz.

En este trabajo intentaremos poner de relieve algunas cuestiones relativas a la discriminación por vejez y, específicamente, al maltrato ejercido contra el adulto mayor. Nos detendremos, especialmente, en la situación de los ancianos institucionalizados, es decir, aquellos que viven - muchas veces abandonados a su suerte- en los denominados "asilos de ancianos", geriátricos o, más técnicamente, Establecimientos de Larga Estadía para Adultos Mayores (en adelante ELEAM).

\section{ALGUNOS DATOS RELEVANTES}

El interés por el estudio de la vejez al que aludimos en los párrafos anteriores, contrasta enormemente con lo que habría sucedido al inicio de la humanidad. En efecto, según Dabove $^{7}$-autora argentina experta en la temática de la ancianidad y a cuyas publicaciones recurriremos frecuentemente- en las sociedades tribales la vejez no siempre fue un problema: hace tres o cuatro millones de años el ser humano tenía muy pocas probabilidades de llegar a una edad avanzada; solo en el neolítico esta situación comienza a cambiar, de tal manera que el promedio máximo de vida eran los cuarenta años.

Esta constatación nos lleva a indagar los motivos por los cuales, en tiempos más modernos, hemos vuelto la mirada hacia este sector de la sociedad. La respuesta la encontramos, fundamentalmente, en el fenómeno del envejecimiento sostenido de la población mundial. En efecto, datos estadísticos señalan que la población mundial aumentará en 2.500 millones de habitantes en los próximos 43 años, pasando de los actuales 6.700 millones a 9.200 millones en 2050. Asimismo, entre 2005 y 2050, la mitad del aumento de la población mundial se deberá al incremento de la población de 60 o más años de edad ${ }^{8}$.

\footnotetext{
${ }^{4}$ Así lo señala Retuerto BuAdes (2000) pp. 597 y ss. Esta autora se refiere a dos modelos en especial: el sueco y el holandés que, participando de una filosofía en común, cual es la protección del anciano contra las enfermedades y la miseria, responden a un sistema de planificación -en el caso sueco- a través del cual el Estado asume la tarea de ofrecer dicha protección, o bien, a un sistema más bien mixto -como es el caso holandés- donde la planificación desempeña un papel marco, que se desarrolla mediante sistemas de asistencia surgidos espontáneamente, la negociación del mercado y el voluntariado.

5 CiUro señala que el que se abogue por un Derecho de la Ancianidad no quiere decir que se requiera abandonar, por ejemplo, el Derecho de Familia o el Derecho de la Previsión Social, sino mostrar que sus soluciones pueden ser perfeccionadas a la luz de una perspectiva profunda e integral de la consideración específica de la situación del anciano. Ciuro Caldani (1992) pp. 35, 36 y 39. Asimismo, Linacero De LA FuEnte aboga por una "Convención de los derechos de la Tercera Edad" en el ámbito del Derecho Internacional, y por una "Ley de Protección social, económica y jurídica de las Personas Mayores" en el plano interno. LiNACERO DE LA FUente (2004) p. 2263. Es más, haciendo un símil con la protección de la infancia, propugna el establecimiento de un "interés superior del anciano". Sobre este tema, vid. CiURO CALDANi (1994) pp. 7-11 y DABOVE (2000a) pp. 1021-1027.

${ }^{6}$ Retuerto (2000) pp. 597 y ss. y Ciuro (1992) p. 39.

7 Dabove (2005) p. 124.

${ }^{8}$ Según las Previsiones demográficas Mundiales. Revisión de 2006 de Naciones Unidas.
} 
Las estadísticas nacionales demuestran que Chile no permanece ajeno a este fenómeno. De hecho, hasta hace un par de décadas solíamos escuchar que el "viejo continente" se envejecía cada vez más y que la tasa de natalidad disminuía vertiginosamente en la gran mayoría de los países europeos. Sin embargo, desde hace un tiempo esa realidad dejó de sernos extraña. El aumento en la esperanza de vida, la disminución de la natalidad y los bajos índices de mortalidad infantil son las causas principales del envejecimiento de la población en América Latina y, por cierto, en Chile9. Así, se ha señalado que el nivel de envejecimiento que Europa logró en dos siglos, América Latina lo alcanzará en solo cincuenta ${ }^{10}$.

Los cambios producidos y proyectados en la pirámide de la población son decidores. Se calcula que en el Chile del año 2010 existirán 50 adultos mayores por cada 100 menores de 15 años y que en el año 2040 estas cifras prácticamente se igualarán. En efecto, entre los años 1950 y 2002 -año en que se llevó a cabo el último censo- las personas mayores de 60 años aumentaron en nuestro país de un $6,8 \%$ a un $11,4 \%$. Se proyecta que, para el 2025, esta cifra alcance el 16\% de la población total chilena.

Por otra parte, cabe tener en cuenta que hombres y mujeres no envejecen al mismo ritmo. Así, la población total de 65 años y más, estimada a junio de 2005, es de 1.290.181, de la cual son hombres un $42,2 \%$ y mujeres un $57,7 \%{ }^{11}$.

Asimismo, datos más recientes de la Encuesta CASEN de 2006 nos dicen que los adultos mayores en Chile suman 2.100.378. El 56\% de ellos son mujeres y más del 60\% de estas superan los 76 años.

La Encuesta revela también que más de la mitad de los hogares unipersonales están constituidos por adultos mayores y poco menos de un quinto de ellos por personas que superan los 75 años.

Por otra parte, el alto grado de participación de este sector en las organizaciones sociales (más de un 35\%) pone de manifiesto la creciente concienciación de este sector en el ejercicio de sus derechos y las prestaciones sociales y comunitarias existentes. A modo de ejemplo, entre 1990 y 2006, la población mayor de 60 años que se realizaba exámenes preventivos creció del 15,3\% al 25\%. En el resto de la población este aumento solo fue de dos cifras porcentuales.

\footnotetext{
${ }^{9}$ En efecto, las modificaciones en el tamaño y composición por edades de la población obedece, principalmente, al descenso brusco y sostenido de la fecundidad a partir de 1964 y al aumento en la esperanza de vida a partir de 1950. Instituto Nacional de Estadísticas (INE) (1999).

10 Enríquez Rosas y Alderete GonZález (2003) p. 3.

11 Según cifras del Instituto Nacional De Estadísticas (INE) (en línea) [fecha de consulta: 22 de julio]. Disponible en [http://www.ine. cl/canales/elemento_persistente/preguntas_frecuentes/ preguntas_frecuentes. php]. Asimismo, en el año 2002, los adultos mayores sobre 60 años alcanzaban 1.717.478, de los cuales el 55,8\% eran mujeres (InstituTo NACiONAL DE ESTADísticAs (INE) (en línea) [fecha de consulta 22 de julio]. Disponible en [http://www.ine. cl/canales/chile_estadistico/ estadisticas_sociales_culturales/adultosmayores/pdf/cifrasmayores.pdf].
} 


\section{CONCEPTO DE PERSONA MAYOR}

Considerando los datos estadísticos mencionados en el epígrafe anterior, cabe preguntarse quiénes son las "personas mayores", "adultos mayores", "ancianos" o "viejos" a que estas cifras se refieren, sobre todo considerando que el espectro de la ancianidad tiende a ampliarse progresivamente.

Así, a la llamada "tercera edad", denominación que está asociada a las personas que han jubilado pero que pueden aún trabajar pues cuentan con una buena salud física y mental y que ha sido, por cierto, incorporada en algunos textos constitucionales ${ }^{12}$, procede ahora la "cuarta edad", constituida por los adultos de aproximadamente 80 años que, por razones de enfermedad o discapacidad, han pasado a ser "dependientes" 13 .

La dificultad en la determinación de la edad en la que se cruza el umbral de una etapa del desarrollo evolutivo humano para pasar a otra ${ }^{14}$, se ve reflejada en la falta de uniformidad de la ley cuando intenta definir o referirse a distintas categorías etarias. Así sucede, como veremos, con el paso de la niñez a la adolescencia, a la juventud, a la "joven adultez" y a la ancianidad.

El Derecho da cuenta de que estas determinaciones son siempre arbitrarias y variables. Sabemos que, conforme al artículo 26 del Código Civil, es infante o niño el menor de 7 años; que es impúber la mujer menor de 12 años y el varón menor de 14; y mayor de edad el que ha cumplido los 18 , de forma que, a partir de este momento, se alcanza la plena capacidad civil. Sin embargo, la Ley 19.968, de Tribunales de Familia, de 2004, reconociendo la autonomía progresiva de los niños, niñas y adolescentes, ha pasado a designar, con estas denominaciones, a todo ser humano que no ha cumplido los 14 años, en el primer caso, y al que sí los ha cumplido, en el segundo, hasta su mayoría de edad. Asimismo, la Ley 20.084, de 2005, establece los 14 años como el momento a partir del cual puede configurarse la responsabilidad penal adolescente. La diferencia en el establecimiento de estas edades dispares obedece, precisamente, a que los criterios utilizados en su determinación son diversos dependiendo del ámbito regulado por la ley: propiamente civil, de familia y penal, y de la época de su dictación.

Pues bien, en lo que a la etapa evolutiva de la vejez se refiere, el Diccionario de la Real Academia Española de la Lengua define la "ancianidad" como el "último período

12 Así sucede en la Constitución española de 1978 (artículo 50) y portuguesa de 1976 (artículo 72), aunque se trata de una denominación que ha sido criticada en la doctrina. En este sentido, SIERRA GIL DE LA Cuesta (2001) p. 87.

13 A la "primera edad" pertenecen los jóvenes que no pueden valerse económicamente por sí mismos; abarca desde el nacimiento hasta la época en que se concluye la educación y se ingresa a la vida laboral. La "segunda edad" comprende la población económica y laboralmente activa y sobre ella recae la mantención de la calidad de vida de las otras tres edades. Esta descripción es efectuada por Drane (2000) p. 99. Por su parte, la dependencia ha sido definida, como "la necesidad de ayuda o asistencia importante para las actividades de la vida cotidiana", y, más específicamente, como "un estado en el que se encuentran las personas que por razones ligadas a la falta o la pérdida de autonomía física, psíquica o intelectual, tienen necesidad de asistencia y/o ayudas importantes a fin de realizar los actos corrientes de la vida diaria y, de modo particular, los referentes al cuidado personal" (Recomendación sobre Dependencia, Comité de Ministros del Consejo de Europa de 18 septiembre de 1998, Rec(98)9e, pp. 50-51). 
de la vida ordinaria del hombre, y la "senectud", como el "período de la vida humana que sigue a la madurez". Por otra parte, se ha señalado que "anciano" viene de la lengua romance "anzi", que significa "antes". Así, según Dabove ${ }^{15}$, la ancianidad denota un concepto que señala la relación del ser humano con el tiempo: la persona anciana es la que cuenta con un "antes".

Veamos algunas referencias a la tercera edad en nuestra legislación, que, como veremos, no guarda armonía conceptual en este aspecto.

En primer lugar, el artículo 223 del Código Civil, que consagra el deber de asistencia y socorro, señala que aunque la emancipación confiera al hijo el derecho de obrar independientemente, queda siempre obligado a cuidar de sus padres en su anciani$d a d$, en el estado de demencia, y en todas las circunstancias de la vida en que necesitaren sus auxilios. Se trata de una norma cardinal en la materia que pretendemos abordar pues, al igual que el deber de respeto consagrado en el artículo 222 del mismo cuerpo legal, se trata de un derecho-deber que se prolonga indefinidamente en el tiempo, y que, al hacer mención al cuidado en general, supera las obligaciones de carácter tradicionalmente patrimonial debidas en virtud de alimentos legales a los ascendientes que se encuentren en situación de necesidad.

Las menciones más indirectas a la tercera edad las encontramos en normas como el artículo 456 bis del Código Penal, relativo a los delitos de robo y hurto, que señala como circunstancia agravante que la víctima sea anciano, sin determinar una edad concreta.

Otra referencia, aún indirecta, la encontramos en el Código Civil en materia de muerte presunta. El artículo 82 de este cuerpo legal establece que el juez concederá la posesión definitiva, en lugar de la provisoria, si, cumplidos los cinco años desde la fecha de las últimas noticias, se probare que han transcurrido 70 desde el nacimiento ${ }^{16}$. Esta norma obedece a que, claramente, las expectativas de vida en la época de la dictación del Código de Bello eran menores ${ }^{17}$.

Otra mención a la mayor adultez la encontramos en la Ley de Adopción (artículos 20 y 31), que establece una edad mínima y máxima para adoptar, 25 y 60 años respectivamente, apartándose así de las legislaciones que sirvieron de inspiración al legislador, como la argentina y española, que no hacen esta exigencia ${ }^{18}$. En esta parte, la norma chilena determina, a

\footnotetext{
14 De hecho, en vez de especificar edades determinadas, se detectan cinco fases críticas del ciclo vital humano: el nacimiento, la madurez, la reproducción, la vejez y la muerte. Así lo señala HoebeL (1961) pp. 403 y ss., cit. por DABOVE (2005) p. 122.

15 DABOVE (2005) p. 103.

${ }^{16}$ En este punto, la legislación argentina es más moderna: la norma fija los 80 años de edad. El artículo 30 de la Ley 14.394 establece que: "Transcurridos cinco años desde el día presuntivo del fallecimiento u ochenta desde el nacimiento de la persona, quedará sin efecto la predotación prescrita pudiendo desde ese momento disponerse libremente de los bienes".

17 De acuerdo a los datos que nos entrega el Anuario Nacional Estadístico, a fines del siglo XIX la esperanza de vida en Chile era de 27-28 años [fecha de consulta: 22 de julio]. Disponible en [http:// www.memoriachilena.cl/temas/dest.asp?id=saludpublicapoblacion]. Conforme a las cifras del INE, en el quinquenio 1970-1975, la expectativa de vida era de 63,6 años para ambos sexos; en el periodo comprendido entre 1980-1985 ascendió a 70,7 años; y entre los años 2000-2005 subió a poco más de 77 años como promedio (74,8 para los hombres y 80,8 para las mujeres).
} 
nuestro juicio, una edad bastante más temprana que la considerada como constitutiva de ancianidad en otras normas y, en general, por la doctrina más especializada en la materia.

En efecto, a nivel constitucional, se han establecido limitaciones para el ejercicio de ciertos cargos basadas en la edad que superan los 60 o 65 años, lo que no estuvo exento, en su momento, de serias críticas que alegaban una discriminación arbitraria en razón de edad ${ }^{19}$. En efecto, el artículo 80 de nuestra Carta Fundamental establece los 75 años como causal de cese en las funciones de los jueces; el artículo 84 inciso primero fija la misma regla respecto de los fiscales regionales y adjuntos; lo mismo sucede con los ministros del Tribunal Constitucional (inciso tercero, parte final del artículo 92), con el Contralor General de la República (artículo 98 inciso segundo, parte final) y, aunque ya no en el texto constitucional, con los Auxiliares de la Administración de Justicia (artículo 495 bis Código Orgánico de Tribunales).

Por último, la Ley 19.828, que crea el Servicio Nacional del Adulto Mayor, define a este como toda persona que ha cumplido los 60 años, sin distinción entre hombres y mujeres (a diferencia de lo que ocurre en materia de jubilación, en que las mujeres acceden a ella a los 60 años pero los hombres a los $65^{20}$ ).

Como vemos, no queda clara la razón de la determinación de estas edades tan diversas, así como no es fácil fijar una edad a partir de la cual una persona pasa a ser "adulto mayor". Esto se debe, entre otras razones, a que no es lo mismo "edad biológica" y "edad cronológica" 21 . La vejez no constituye solo un proceso biológico; muy por el contra-

\footnotetext{
${ }^{18} \mathrm{Al}$ respecto, cierta doctrina, ha señalado que establecer una norma de este tipo es positivo pues con ella se evitaría una brecha generacional demasiado amplia entre adoptante y adoptado y, por otra parte, la posibilidad de muerte del adoptante, que podría producir, a corto plazo, una nueva situación de desamparo del menor, con las consiguientes consecuencias psicológicas negativas que ello conlleva. En este sentido, Medina y OTROS (1998) p. 103.

${ }^{19}$ De hecho, en países como Argentina, la jurisprudencia se refirió a este tipo de inhabilidades estableciendo la existencia de una discriminación arbitraria en razón de la edad. La Corte de Apelaciones de Buenos Aires calificó de discriminatoria y atentatoria contra el derecho a trabajar y a la igualdad ante la ley, la norma que establece el límite de cuarenta y cinco años como requisito para la inscripción en los listados oficiales de ingreso a la docencia. Las mismas garantías resultarían vulneradas, conforme a la Corte Suprema de Justicia de dicho país, en primer lugar, por la norma legal que establece la edad de 75 años como una inhabilidad para ejercer funciones notariales, por presumir de derecho que quienes alcanzan dicha edad se encuentran incapacitados para ejercer dichos cargos, y, en segundo lugar, por la reforma declarada inconstitucional por el mismo Tribunal, que limitó, en la Constitución, la permanencia de los jueces de la Corte hasta la edad de setenta y cinco años. Fallos citados por Kemelmajer De CARLucci (2006) p. 51.

20 Cabe tener en cuenta que, en ambos casos, cada vez son más los chilenos que, superando esa edad, continúan trabajando: de acuerdo a los datos de la Encuesta CASEN de 2006 la participación laboral de la población nacional de más de 65 años es actualmente del 18,5\%, cifra muy distinta al 14,6\% de participación de este grupo en el año 1990.

21 En efecto, se distingue entre edad cronológica, edad biológica, la noción médica de la ancianidad, y el concepto cultural de ancianidad. Así, Morelli (1999) pp. 33-35. Por su parte, Kemelmajer De CarluCCI señala que jurisprudencia argentina reiterada ha distinguido entre simple ancianidad y senilidad calificada. La primera no conduciría necesariamente a la senilidad patológica, pues la vejez no es sinónimo de enfermedad, incluso cuando implica disminuciones de facultades de la persona. Solo la senilidad calificada acarrearía la incapacitación o inhabilitación según el grado que presente. KEMELMAJER (2006) p. 40. Por su parte, STANZIONE alude a la edad biológica y edad funcional. Esta última se ubicaría entre los cinco años anteriores y cinco posteriores a la edad cronológica. STANZIONE (2007) pp. 55 y ss., en especial, p. 58.
} 
rio, involucra también una serie de cambios a nivel mental, aspectos psicológicos, sociales, familiares, laborales, etc. Solo un ejemplo: la edad de jubilación de la población económicamente activa suele determinarse alrededor de los 65 años, los que, conforme a la edad cronológica, marcarían el paso de adulto joven a adulto mayor; sin embargo, la Organización Mundial de la Salud (OMS) ha fijado el comienzo de la ancianidad en los 75 años ${ }^{22}$.

En suma, no hay armonía en nuestro ordenamiento jurídico, de manera que solo tentativamente podríamos decir, con pretensiones de generalidad, que es adulto mayor la persona que ha cumplido los 60 años, tal como lo señala la mencionada Ley 19.828, que es la norma positiva más reciente y específica en la materia.

\section{EL MALTRATO CONTRA LOS ADULTOS MAYORES}

\subsection{El MALTRATO COMO EXPRESIÓN DE LA DisCRIMINACIÓN CONTRA LOS ADULTOS MAYORES}

El interés por la protección del adulto mayor no nace solo como reacción a la realidad demográfica incontestable que hemos descrito más arriba. La apelación a un mayor desarrollo normativo a favor de este sector etario es también consecuencia de la gestación de los llamados derechos de "tercera generación" 23 y del proceso de "especificación" de los derechos humanos de ciertos $\operatorname{colectivos}^{24}$, es decir, de la atribución de determinadas prerrogativas a aquellas personas que, por determinadas circunstancias, pueden encontrarse en una posición desmedrada dentro de la sociedad. Se trata, en suma, de una consecuencia de la distinción -generada a partir de la segunda mitad del siglo XX- de ciertos intereses propios de dichos grupos y su especial vulnerabilidad ${ }^{25}$.

Lo cierto es que la protección de la ancianidad constituye una medida de acción afirmativa, como respuesta al sinnúmero de situaciones en que estas personas son actualmente discriminadas. Su mayor fragilidad, la precariedad económica que muchas veces sufren y el abandono social y familiar, hacen del anciano un sujeto susceptible de ser discriminado en razón de su vejez, fenómeno denominado "edadismo ${ }^{26}$. Es por ello que a la constatación siempre positiva de la mayor esperanza de vida actual, debe seguir la interrogante de si con ella aumenta o no la "calidad de vida", pues las condiciones en que un ser humano vive determinan también cuánto vive.

El profesor $\operatorname{Lolas}^{27}$ señala que debido al marcado "juvenilismo" del posmodernismo occidental, el adulto mayor se ha convertido en un estorbo, en una incomodi-

\footnotetext{
22 Kemelmajer (2006) p. 40.

${ }^{23}$ Denominación acuñada por VASAK (1977) p. 29.

${ }^{24}$ En efecto, frente a la noción de "generaciones de derechos" algunos autores, descartando la existencia de categorías de los mismos, prefieren hablar de "etapas" en la evolución de los derechos humanos, distinguiéndose las fases de positivización, generalización, expansión, internacionalización y especificación. Al respecto, PeCes-BArba (1988) pp. 241-262; Pérez LuÑo (2003) pp. 108-130; y Ara Pinilla (1990) pp. 133 y 134.

25 ViVANCO (2003) p. 193 y DABOVE (2005/2006) pp. 155 y ss.

26 Así lo define Dabove (2005/2006) p. 159. Sobre este fenómeno, Vid. SaGrega (1992) pp. 105 y ss.

27 Lolas STEPKe (2006) pp. 39-40. En este mismo sentido, MorCillo (2004) p. 846.
} 
dad que desafía la ciencia y amenaza el bienestar social. Un fenómeno biológico -el envejecimiento- se convierte entonces en un fenómeno social, con "signo" positivo para algunos y negativo para otros. De este modo, existiría una muerte "social" y una muerte "real" o biológica. En la primera se encontrarían, por ejemplo, la postergación de los ancianos en el diseño de políticas de salud y atención médica, que dan preferencia a los más jóvenes por sobre los adultos mayores; la exclusión laboral, a partir de los 45 o 50 años y que alcanza su plenitud hacia los 60 o 65 años; y, además, el aumento en los montos de las cotizaciones de salud previstos por las Instituciones de Salud Previsional (ISAPRES) 28 .

Pues bien, a mi juicio, una de las consecuencias más graves de la discriminación por vejez es el maltrato físico y psicológico que sufren los adultos mayores. El maltrato es condenable no solo porque lesiona el derecho a la vida o a la integridad física o psicológica, sino también porque quien lo ejerce no mira de igual a igual a su víctima, porque no se está en una relación de paridad con el anciano. Las situaciones de abuso suelen estar ligadas a relaciones desiguales en la familia o el entorno social, de ahí que quienes más las sufren sean las mujeres, niños, ancianos y discapacitados ${ }^{29}$. Ello explica que el maltrato sea más frecuente en el mismo seno familiar o en los ambientes en que el anciano es cuidado cotidianamente. La doctrina especializada ha señalado que los informes relativos a los malos tratos indicarían que la violencia ejercida contra los ancianos oscila entre un 3\% y 10\%, del cual el $37 \%$ es ejercido por los hijos, el $13 \%$ por los cónyuges y el $11 \%$ por otros familiares ${ }^{30}$, es decir, por los más cercanos.

En todo caso, la enorme mayoría de los países que cuentan con legislación para prevenir y erradicar la violencia intrafamiliar, esta aún se centra en las mujeres y los niños. De hecho, los estudios e investigaciones sobre la violencia intrafamiliar se focalizaron, en un inicio, en el maltrato infantil -alrededor de los años sesenta- para, poste-

\footnotetext{
28 Algunos de estos ejemplos se encuentran desarrollados en FigUEROA (2007) pp. 335 y ss. En cuanto a las alzas de los planes de salud ofrecidos por las Isapres, cabe señalar que el 26 de junio de 2008, el Tribunal Constitucional, en causa Rol 976-07-INA, acogió el requerimiento de inconstitucionalidad del artículo 38 ter de la Ley 18.933 (Ley de Isapres) por ser contrario al artículo 19 n 9 de la Constitución que consagra el derecho de la persona a elegir el sistema de salud que desee. La primera de estas normas, que contempla las tablas de factores para fijar los montos del contrato de salud, habrían permitido cuadriplicar el valor del plan por el solo hecho de haber cumplido la requirente los 60 años de edad.

${ }^{29}$ La noción entre discriminación y violencia ha sido abordada por tratados internacionales. El artículo 1 de la Convención sobre la Eliminación de todas las Formas de Discriminación contra la Mujer, de 1979, define la discriminación en contra de esta incluyendo la violencia basada en el sexo. El órgano vigilante de este instrumento ha señalado que "La violencia contra la mujer es una forma de discriminación que impide gravemente que goce de derechos y libertades en pie de igualdad con el hombre"; "El artículo 1 de la Convención define la discriminación contra la mujer. Esa definición incluye la violencia basada en el sexo, es decir, la violencia dirigida contra la mujer porque es mujer o que la afecta en forma desproporcionada. Incluye actos que infligen daños o sufrimientos de índole física, mental o sexual, amenazas de cometer esos actos, coacción y otras formas de privación de la libertad. La violencia contra la mujer puede contravenir disposiciones de la Convención, sin tener en cuenta si hablan expresamente de la violencia" (Recomendación General No 19: violencia contra la mujer, Comité de la Convención sobre la Eliminación de todas las Formas de Discriminación contra la Mujer, adoptada en el $11^{\circ}$ periodo de sesiones, año 1992, párrafos 1 y 6).

${ }^{30}$ Así lo afirma Rubio (2005) p. 118.
} 
riormente, extenderse a la violencia ejercida contra la mujer en el seno de la pareja -en los años setenta- y solo en los años ochenta y noventa a los adultos mayores ${ }^{31}$.

Por cierto, los niños, mujeres, ancianos y discapacitados no recibieron una protección jurídica especial en los primeros ordenamientos constitucionales liberales ${ }^{32}$. Los derechos humanos básicos fueron reconocidos a hombres y mujeres sin mayor consideración de sus especiales circunstancias. En efecto, en otros países, pese a contar con una tradición jurídica más asentada en estas materias, se ha sostenido que las normas que protegen a los mayores se desprenden de textos legislativos dirigidos a garantizar los derechos de las mujeres, niños y discapacitados, o de la población en general, sin advertir si la solución que se propone es eficaz y si se adapta, realmente, a las necesidades del colectivo para quien se legisla ${ }^{33}$.

A nivel nacional, las escasas exploraciones llevadas a cabo indican que, prácticamente, uno de cada tres ancianos sufriría algún tipo de maltrato. Así, en el año 2005 se dieron a conocer tres estudios efectuados, en épocas distintas, en Renca, Valdivia, Concepción y Temuco, los que arrojaron que más del 30\% de los adultos mayores encuestados habían sufrido algún tipo de maltrato (en su gran mayoría de carácter psicológico); cifras que, según los expertos, coincidirían con otras investigaciones llevadas a cabo en Argentina y Brasil. Asimismo, estos estudios revelaron que sobre el 60\% de los adultos mayores no denuncia porque no puede o no sabe hacerlo; el maltrato no sería exclusivo de los ancianos dependientes; cruzaría todos los estratos socioeconómicos y sobre el $35 \%$ de los agresores serían mayoritariamente mujeres ${ }^{34}$.

En efecto, los datos de Carabineros de Chile indican que las denuncias por violencia intrafamiliar en que la víctima es un adulto mayor escasamente superan el $1 \% 35$. Algunas de las razones que explican esta escasez son la negación de la situación de maltrato; el miedo a las represalias, a ser institucionalizado, al desafecto de la familia, a perder contacto con el cuidador; la dependencia económica del cuidador; la vergüenza de que la gente se entere que está siendo maltratado (sobre todo si quien maltrata es un familiar); los sentimientos de culpa acerca de la propia situación de maltrato; el escepticismo frente a la respuesta que la denuncia va a provocar en los demás; la mala salud física o alguna clase de deterioro cognitivo; el desconocimiento de los servicios que puede utilizar ante estas situaciones; etc. ${ }^{36}$.

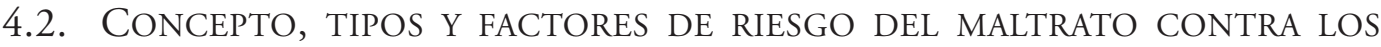 ADULTOS MAYORES}

Si bien no existe acuerdo absoluto en la conceptualización y tipología del maltrato contra el adulto mayor, se ha alcanzado relativo consenso en cuanto a que constituye un

\footnotetext{
${ }^{31}$ Rubio (2005) p. 114. Vid. también IMSERSO (2007) p. 2.

32 Vivanco (2003) p. 193

33 Muñoz TORTOSA (2004) pp. 171-172.

${ }^{34}$ Estos datos constan en SerVicio NaCiOnal Del Adulto Mayor (2007a).

35 Conforme a la Información Anual de Carabineros 2007, de un total de 108.538 denuncias recibidas en dicho año, el 1,2\% fue interpuesta por adultos mayores.

36 Elementos descritos en IMSERSO (2007) p. 12.
} 
fenómeno multicausal. Como veremos, en él convergen una serie de elementos de índole personal, familiar, social y cultural. Así, la Declaración de Hong Kong de la Asociación Médica Mundial sobre el maltrato de ancianos ${ }^{37}$ expresa que las personas ancianas pueden sufrir problemas patológicos, tales como, alteraciones motrices y físicas y trastornos que requieren de asistencia en sus actividades diarias. Esta condición puede llevarlos a un estado de dependencia, lo que, a su vez, puede generar que sus familias y la comunidad toda los consideren como una carga, reduciendo al mínimo el cuidado y los servicios que se les prestan.

En cuanto al concepto de maltrato contra el adulto mayor, este varía dependiendo de la óptica desde la cual es analizado. Así, los enfoques connotativos pondrían mayor atención en los efectos que producen los malos tratos; en cambio, las definiciones estructurales se centrarían en los múltiples sentidos del maltrato; y, por último, las conceptualizaciones descriptivas se limitarían a establecer listados relativos al comportamiento del agresor ${ }^{38}$.

Durante la II Asamblea Mundial sobre el Envejecimiento, realizada en Madrid en el año 2002, se señaló que una definición de maltrato contra las personas de edad que ha ido ganando apoyo en los últimos 20 años, es la que lo conceptualiza como "cualquier acto único o repetido o falta de acción apropiada que ocurra en cualquier relación de confianza que cause daño o angustia a una persona mayor"39. Como puede apreciarse, tanto la acción como la omisión pueden constituir maltrato; a su vez, este puede generarse a consecuencia de un acto aislado como de un comportamiento habitual; puede provenir bien de un familiar como de un extraño, producirse en el seno de la familia como en una institución; y, por último, la conducta del maltratador se caracteriza, esencialmente, por causar daño, el cual puede ir, como veremos, desde la agresión física al maltrato emocional, espiritual o psicológico, como la angustia provocada al adulto mayor mediante esa acción.

En efecto, en cuanto a los tipos de maltrato, existe abundante bibliografía especializada dirigida a describir las diversas manifestaciones que puede presentar la violencia contra el adulto mayor ${ }^{40}$. Revisemos algunos de ellos.

En primer lugar, el maltrato físico implica una acción que causa deterioro físico o daño corporal (golpear, abofetear, quemar, etc.). Constituyen este tipo de maltrato, la violencia física propiamente dicha, la sobre o submedicación y el abandono alimenticio. Por su parte, el maltrato psicológico y/o emocional se ejerce a través de la violencia psicológica, la agresión verbal, el uso de amenazas (de institucionalización, por ejemplo), obligación

${ }^{37}$ Adoptada por la 41a Asamblea Médica Mundial de Hong Kong, de septiembre de 1989; revisada en la 126a Sesión del Consejo, en Jerusalén, Israel, en mayo de 1990, y en la 170a Sesión del Consejo en Divonne-les-Bains, Francia, en mayo de 2005.

38 Rubio (2005) pp. 116-117.

39 Se trata de una definición dada por la entidad benéfica británica Action on Abuse of Older Persons. Vid. Comisión de Desarrollo Social constituida en Comité Preparatorio de la Segunda Asamblea Mundial sobre el Envejecimiento. Segundo periodo de sesiones. Documento del Consejo Económico y Social de Naciones Unidas, E/CN.5/2002/PC/2.

40 Se refieren a los tipos de maltrato indicados: CADOCHE (2002) p. 96; RUBIO (2005) p. 117; RIVERO (2002) pp. 295-296; y en IMSERSO (2007) pp. 7 y ss. 
de presenciar maltrato infligido a otras personas, la falta de privacidad, la humillación, la burla, los silencios, actos verbales y no verbales intencionales que causan miedo, estrés, pena, etc. El maltrato espiritual consiste en negar al adulto mayor la oportunidad de participar en la toma de decisiones que conciernen a su vida, impidiendo, por ejemplo, ejercer con libertad la propia creencia u orientación religiosa, o la elección de una pareja. El maltrato sexual consiste en el contacto y/o comportamiento sexual no consentido con adultos mayores, bien porque estos no están en condiciones de dar su consentimiento o bien porque el contacto sexual se produce mediando engaño, situaciones de las que las mujeres ancianas son víctimas con mucha más frecuencia. En quinto lugar, el maltrato patrimonial se verifica, generalmente, mediante el uso no autorizado de los recursos económicos de la persona mayor, el manejo ilegal o inapropiado de los mismos o la obligación impuesta al adulto mayor de modificar su testamento. Generalmente, estos últimos delitos quedan amparados por excusas legales absolutorias, o bien, se esconden tras falsas interdicciones por demencia o falsas atribuciones de enfermedades mentales con el objeto de obtener una orden judicial de internación en un establecimiento psiquiátrico.

Más específicamente, se distingue el maltrato estructural o societario, que tiene lugar desde y en las estructuras de la sociedad mediante normas legales, sociales, culturales y económicas. Existe también la denominada obstinación diagnóstica, que dice relación con la realización de pruebas y exámenes para aumentar el conocimiento de la enfermedad de un adulto mayor, sin que sea posible prever que ello redunde en beneficios reales para este. La obstinación terapéutica, por su parte, consiste en el uso desproporcionado de medios destinados a prolongar artificialmente la vida de una persona mayor con una enfermedad terminal. Asimismo, la negligencia se traduce en el rechazo, negativa o error, voluntario o involuntario, de parte de la persona a cargo del cuidado del adulto mayor, a iniciar, continuar o completar la atención que este requiere. Se distingue la negligencia física, emocional o psicológica, y económica o material. Y, por último, el maltrato por abandono, constituye el abandono de un adulto mayor por una persona que ha asumido la responsabilidad de su cuidado o por parte de la persona que posee la custodia física de aquel ${ }^{41}$.

Como vemos, se trata de abusos que, en definitiva, vulneran derechos humanos básicos y conducen a la exclusión y aislación social y familiar.

Los elementos que indican una mayor propensión a sufrir o causar el maltrato están vinculados a la vulnerabilidad social y económica, a los índices de fragilidad física y psíquica y a las progresivas pérdidas sensoriales ${ }^{42}$.

Veamos algunos factores de riesgo.

En primer lugar, cabe señalar que una de las variables predictoras es el género. Las investigaciones señalan que si bien este tipo de maltrato es ejercido tanto contra hom-

\footnotetext{
41 En un estudio del Servicio Nacional del Adulto Mayor se señala que el 10\% de los adultos mayores estudiados no vive integrado a su familia pese a compartir domicilio con ella: no mantiene vínculos de convivencia cotidiana como cocinar, conversar, ver televisión, etc., situación que aumenta a medida que el adulto mayor es más anciano. Servicio NaCional Del Adulto Mayor (2007).

42 Rubio (2005) p. 120.
} 
bres como contra mujeres ancianas, las estadísticas demuestran que estas sufren más este tipo de violencia. Esto se explicaría, a mi juicio, en primer término, por el contexto sociológico que determina el fenómeno de la violencia en contra de las mujeres en general y cuyo análisis excede el objeto de este trabajo ${ }^{43}$. En segundo lugar, porque las mujeres tienen mayor esperanza de vida $y$, por ende, al tratarse de un grupo más numeroso, la probabilidad de sufrir maltrato es mayor. Por otra parte, se señala que es más frecuente que la mujer requiera atención sociosanitaria debido a la mayor posibilidad de que se trate de maltrato físico. Asimismo, se ha detectado que el hombre es más reticente que la mujer a denunciar debido a la vergüenza que situaciones de este tipo le provocan y al temor de que su entorno no preste crédito a sus afirmaciones ${ }^{44}$.

Otros factores de riesgo son la edad, pues a mayor edad mayor riesgo; el estado civil, ya que las personas casadas estarían más expuestas a sufrir maltrato; determinados rasgos de la personalidad, como la tendencia a autoculparse o la lealtad excesiva frente al maltratador; la presencia de comportamientos provocadores y/o agresivos causados por el padecimiento de algún grado de demencia; el deterioro cognitivo, como el alzheimer; la mala salud; problemas de comunicación, dependencia, etc. ${ }^{45}$.

En el contexto familiar, los principales factores de riesgo detectados son la existencia de alguna enfermedad, la lentitud funcional, la pérdida intelectual, el comportamiento violento o los trastornos mentales, la dependencia del cuidador respecto de la víctima, la cohabitación, el aislamiento social y el historial de violencia ${ }^{46}$.

Por su parte, uno de los factores de riesgo presente en el responsable del maltrato es, nuevamente, el género, pues las mujeres son las que, mayoritariamente, asumen el cuidado de las personas ancianas, quienes vienen a sumarse al cuidado de los hijos que en la gran mayoría de los casos desarrollan. En efecto, se ha hablado de una verdadera "feminización" del cuidado de los adultos mayores ${ }^{47}$, situación que las haría más proclives a inferir malos tratos.

Entre otros factores de riesgo presentes en el responsable del maltrato se encuentran la inexperiencia en el cuidado de los adultos mayores ${ }^{48}$; la presencia de trastornos psicológicos; ciertos rasgos de la personalidad, como culpar al anciano de la situación o la falta de paciencia; el abuso de sustancias, como el alcohol y/u otras drogas; la presencia se sentimientos negativos, como la ira o la hostilidad; el estrés; la

\footnotetext{
43 Sobre este punto, vid. AMORÓs (1990) p. 10; RiCO (1996); y CEPAL (2007).

${ }^{44}$ IMSERSO (2007) p. 3.

45 Señalados en IMSERSO (2007) p. 10.

46 RUBIO (2005) pp. 120-121.

47 En el estudio del Servicio Nacional del Adulto Mayor que hemos mencionado más arriba, se señala que el $85 \%$ de los adultos mayores estudiados son cuidados por mujeres, fundamentalmente sus hijas (45\%) y cónyuges (11\%). Por otra parte, la mayoría de estas mujeres son de edad adulta (entre 42 y 61 años) y se dedican al cuidado de forma solitaria y exclusiva (p. 156). SERvicio Nacional Del Adulto Mayor (2007) p. 157.

48 Se ha concluido que solo el 7\% de los cuidadores ha recibido alguna capacitación para el cuidado y que las habilidades para esta labor son desarrolladas muchas veces a través del ensayo y el error, lo que puede causar tensión en el cuidador debido a la inseguridad que esta situación le genera, generándose así importantes riesgos para los adultos mayores a su cargo. CrF. Servicio NaCiOnal Del Adulto Mayor (2007) p. 161.
} 
sobrecarga; la dependencia económica de la persona mayor ${ }^{49}$; la presencia de altos niveles de estrés en la vida privada; actitudes negativas hacia los adultos mayores (gerontofobia); escasa capacidad para soportar la frustración; y el denominado "personal quemado"50 o "síndrome de burnout", es decir, el propio estrés que sufren los cuidadores producto del ambiente en que desarrollan sus funciones, situación que genera agotamiento físico, psicológico y profesional y que puede intensificar conductas de maltrato ${ }^{51}$.

Por último, en la situación de cuidado se distinguen los siguientes factores de riesgo: la cantidad de ayuda -formal e informal- recibida por los cuidadores, pues quienes menos ayuda reciben son quienes mayor riesgo de maltratar presentan; la falta de contactos informales y/o formales (aislamiento social); el desgaste de los vínculos intergeneracionales; dificultades económicas ${ }^{52}$; el hecho de que el cuidador y adulto mayor vivan juntos; la calidad anterior y actual de la relación entre cuidador y el adulto mayor; y el hecho de que la vivienda sea compartida por demasiadas personas, lo que generan falta de espacio y de intimidad ${ }^{53}$.

\subsection{El MALTRATO CONTRA LOS ADULTOS MAYORES INSTITUCIONALIZADOS}

\subsubsection{Generalidades}

Los estudios llevados a cabo demuestran que gran parte del maltrato contra el adulto mayor es ejercido en el mismo seno familiar-particularmente por los hijos y el cónyuge ${ }^{54}$ - a través de las diversas manifestaciones que hemos enunciado en el epígrafe anterior. Sin embargo, a esa violencia puede sucederle otra específica manifestación de abandono: las internaciones geriátricas. Es más, en estos casos, la víctima puede llegar a sufrir un doble abuso si los familiares maltratadores son reemplazados por los cuidadores que trabajan en esas instituciones, agudizándose así la situación de violencia. De hecho, hay quienes comienzan a hablar de "geronticidio" para referirse a los

\footnotetext{
49 Enunciados en IMSERSO (2007) pp. 10 y 11.

50 Rubio (2005) p. 121.

${ }^{51}$ Rubio (2005) pp. 120, 121 y 125.

52 Se ha concluido que las personas que cuidan a los adultos mayores son, en su gran mayoría -como ya hemos dicho- mujeres y que ellas presentan una situación de vulnerabilidad económica, provienen del ámbito rural, han sufrido abandono durante su infancia, tienen una baja escolaridad, han padecido deserción escolar, trabajo infantil temprano, y precariedad laboral. En este sentido, se señala que, al proyectar la situación de las personas cuidadoras, puede afirmarse que la realidad de la persona a la que prestan apoyo prácticamente se reproducirá en ellas: serán adultos mayores en situación de precariedad aguda ya que no han contado con ingresos propios ni ahorro para enfrentar la vejez y las posibilidades de construir su familia o vínculos afectivos propios han sido mínimas debido a la intensidad del cuidado prestado al adulto mayor por mucho tiempo. En efecto, en cuanto a este último factor, el estudio arrojó que el $87 \%$ de los cuidadores dedica sus labores al adulto mayor los siete días de la semana; por otro lado, gran parte de estas personas cuidan al anciano las veinticuatro horas del día y, por último, todos ellos lo hacen desde hace años (p. 159). Servicio Nacional Del Adulto Mayor (2007) p. 156.

53 Enunciados en IMSERSO (2007) p. 11.

${ }^{54}$ IMSERSO (2007) p. 1.
} 
asesinatos masivos de ancianos que se han producido en los últimos años en establecimientos de este tipo ${ }^{55}$.

En este sentido, si bien la familia, como célula básica de la sociedad, sigue siendo el principal entorno en que las personas ancianas viven - permaneciendo bajo el cuidado de sus hijos u otros descendientes- ${ }^{56}$, las cifras nos demuestran que un número importante de ellas ha visto transformado su núcleo familiar por el entorno muchas veces desolador del denominado "Establecimiento de Larga Estadía del Adulto Mayor" (ELEAM). Se trata de un fenómeno que obedece a la denominada ruptura de la solidaridad vertical, es decir, a la ausencia de redes primarias de cuidado, que han cedido espacio a la asistencia no consanguínea (solidaridad horizontal) ${ }^{57}$. De hecho, uno de los elementos que intensifican este quiebre es la imposibilidad de asistir a los propios padres debido a la dependencia económica y prolongada presencia de los descendientes en el hogar familiar, realidad conocida como "adultescencia" 58 .

Pues bien, aunque el fenómeno del maltrato contra el adulto mayor nace fundamentalmente al interior de las familias, y pese a que sigue siendo este el principal entorno donde aquel se produce, en lo que va de este siglo, los esfuerzos se han dirigido también a detectar y erradicar la violencia que los ancianos sufren en los espacios extrafamiliares y, fundamentalmente, en las residencias para adultos mayores.

Este fenómeno, denominado "maltrato institucional", ha sido definido como cualquier legislación, programa, procedimiento, actuación u omisión procedente de los poderes públicos o derivado de la actuación individual del profesional o funcionario, que conlleve abuso, negligencia, detrimento de la salud, seguridad, bienestar emocional y físico o que viole los derechos básicos de la persona ${ }^{59}$.

Los antecedentes remotos de denuncia de este tipo de maltrato se remontan a mediados del siglo XIX, específicamente en Inglaterra, donde aproximadamente en el año 1837, comenzaron a conocerse las paupérrimas e inhumanas condiciones en que vivían los internos en los establecimientos acogidos al sistema de Asilo y Leyes para Pobres en Inglaterra ${ }^{60}$.

\footnotetext{
55 BROGDEN (2001) cit. por KINGSTON (2005) pp. 150-151. Este autor alude al dramático suceso acaecido en Dinamarca el año 1997, cuando una enfermera fue acusada de asesinar a más de veinte pacientes de una residencia geriátrica, utilizando una sobredosis de calmantes a base de morfina.

56 En un estudio llevado a cabo en Chile, se llegó a la conclusión de que, en general, se asume como un proceso natural que la familia se haga cargo del cuidado del adulto mayor, aunque es probable que en sectores de mayores recursos económicos exista una tendencia a externalizar esta labor mediante servicios pagados al interior de los hogares (enfermeras o "nanas") o fuera de ellos (establecimientos de larga estadía). Por otra parte, se concluye que en el $90 \%$ de los casos el apoyo que se presta al adulto mayor no es remunerado y que en el $93,7 \%$ es proporcionado por un familiar, pudiendo aseverarse que, en la mayor parte de los casos, estamos frente a "cuidados domiciliarios informales". SERVICIO NACIONAL DeL ADULTO MAYOR (2007) pp. 154 y 155.

57 TOMASEllo (2002) p. 930. Vid. también, LOLAS (2006) pp. 75 y 180 y FANZOLATO (1996) pp. 11-42, en especial, pp. 11-21.

58 Morcillo (2004) p. 844.

59 Concepto enunciado por RUBIO (2005) p. 123.

${ }^{60}$ Kingston (2001) pp. 135-138.
} 
Las razones que conducen a la institucionalización del adulto mayor han sido categorizadas en cuatro grandes grupos: motivaciones históricas, materiales, normativas y, por último, valorativas. Las motivaciones históricas se refieren, por una parte, a la relación entre el pasado particular del anciano, sus familiares y el establecimiento, cuestiones que son claramente condicionantes; $y$, por otra, a la visión de la vejez en el imaginario social universal, lo que incidiría de forma más sutil. Las razones materiales, frecuentemente invocadas, son las circunstancias particulares del anciano y su entorno, como el padecimiento de alguna enfermedad que ocasione una pérdida importante de autonomía. Las motivaciones normativas, en cambio, tienen lugar cuando la internación es adoptada como consecuencia de una decisión judicial, como la orden de internación o la declaración de incapacidad. Por último, las de carácter valorativo son las consideraciones de justicia, salud, bondad, utilidad, cooperación, poder, solidaridad, etc., que cada parte estime oportunas ${ }^{61}$.

Si bien no existen estudios específicos ni estadísticas en la materia, los especialistas señalan que los tipos de maltrato que se dan con mayor frecuencia en este contexto son la infantilización en el trato, la despersonalización en la provisión de servicios, la deshumanización, la privación de la intimidad y la victimización ${ }^{62}$. Por su parte, siguiendo la tipología del maltrato que señalamos anteriormente, es más frecuente el de carácter psicológico y medicamentoso y las restricciones físicas impuestas a los mayores, siendo menor el abuso físico ${ }^{63}$.

Asimismo, el maltrato puede provenir no solo de algún miembro del personal sino también de otro residente, algún visitante voluntario, o bien, de parientes o amigos. De hecho, existe un modelo teórico de maltrato, construido en la década del noventa, que descansa en la existencia de tres niveles estructurales: micro, medio y macro ${ }^{64}$. En el primer nivel el maltrato tiene lugar entre los propios individuos dentro de la institución, por ejemplo, entre el personal y los residentes. En el nivel medio, por su parte, el maltrato se debe al régimen que opera en la institución. Y, por último, en el nivel macro, el maltrato es el resultado del sistema, a través de una legislación deficiente u objetivos erróneos de políticas sociales.

Por último, a los factores de riesgo mencionados anteriormente, se suman, en el caso del maltrato institucional, la falta de recursos económicos, el hacinamiento, la edad avanzada de los usuarios, la preparación deficiente del personal, una inadecuada dirección del centro, actitud negativa del paciente, la conflictividad personal-pacientes y la mala racionalización del trabajo ${ }^{65}$.

\subsubsection{Los Establecimientos de Larga Estadia para Adultos Mayores (ELEAM)}

El Reglamento de Establecimientos de Larga Estadía para Adultos Mayores, contenido en el Decreto 134 de 2005 del Ministerio de Salud ${ }^{66}$, define estas instituciones

\footnotetext{
${ }^{61}$ En esta parte, seguimos a DABOVE (2000) p. 218.

62 Rubio (2005) p. 123.

${ }^{63}$ Rubio (2005) p. 124.

${ }^{64}$ Descrito por Kingston (2001) p. 143.

${ }^{65}$ Rubio (2005) pp. 124-125.

66 Publicado en el Diario Oficial de 15 de marzo de 2006.
} 
como aquellas en que residen adultos mayores que, por motivos biológicos, psicológicos o sociales, requieren de un medio ambiente protegido y cuidados diferenciados para la mantención de su salud y funcionalidad, el cual cuenta con autorización para funcionar en esa calidad otorgada por la Secretaría Regional Ministerial de Salud competente del lugar en que se encuentra ubicado.

Se trata, como salta a la vista, de una definición sumamente descriptiva y formal. Extraña aquí la ausencia de los fines y funciones que deben cumplir estos establecimientos.

En la doctrina, Dabove ${ }^{67}$ se refiere a las posibles conceptualizaciones de los ELEAM. En primer lugar, señala que estos han sido considerados como "viviendas especiales" debido a que su diseño y dinámica deben responder a las características específicas de la persona anciana; de manera que, desde este punto de vista, pueden definirse como "estructuras de acogida gracias a las cuales las personas de edad avanzada pueden abandonar su domicilio de manera provisional o definitiva para ingresar a instituciones colectivas o semicolectivas".

Si bien este concepto es menos descriptivo que el contenido en nuestro Reglamento, tampoco establece sustancialmente las funciones que están llamados a cumplir estos establecimientos. En este sentido, Dabove señala que, en realidad, los hogares de ancianos constituyen más bien verdaderas instituciones, pues son estructuras materiales y formales de acogida, que impactan sobre la conducta de las personas vinculadas a las mismas (ancianos residentes, personal de servicio y visitantes), en función de una idea fuerza: la conservación del propio anciano como sujeto titular primario. En efecto, los ELEAM presentarían tres dimensiones esenciales: la realidad social, los valores y las normas. La realidad social es la necesidad de alojamiento y cuidado de estas personas; los valores están dados por los fines y exigencias de justicia particularizadas a través de los cuales se organizan estos establecimientos; y, por último, las normas están dadas por el marco jurídico regulatorio a que estos lugares deben someterse.

Finalmente, estos establecimientos constituirían organismos prestadores de servicios sociales en cuanto son instituciones destinadas a brindar un servicio de beneficio para la población en general, ya sea que se organicen como órganos estatales u órganos privados. En efecto, los ELEAM pueden tener un carácter público, privado o mixto, atendiendo a quienes son los encargados de llevar adelante la planificación u objeto social y conforme al origen del patrimonio utilizado.

Esta clasificación tiene importancia a efectos de determinar la naturaleza jurídica del vínculo que se genera. En este sentido, se trataría de un contrato de prestación de servicios geriátricos, de carácter bilateral, oneroso, consensual, no formal, de tracto sucesivo y de cambio. Si la prestación es otorgada por un establecimiento privado, el servicio se sujeta a las normas generales de los contratos y, en especial, a las normas de protección al consumidor ${ }^{68}$. Si se trata, en cambio, de una residencia estatal, existirá un

67 Concepto reproducido por DABOVE (2005a) pp. 51 y ss.

68 FrUSTAGLi y HeRnÁNDEZ (2005) p. 80. Estos autores definen este contrato como aquel que se configura cuando una empresa -denominada generalmente residencia u hogar- se obliga a prestar a favor de personas ancianas, servicios de alojamiento, alimentación, higiene, recreación, atención médica y psicológica no sanatorial -en forma permanente o transitoria - y la otra, se obliga a una suma determinada de dinero. 
contrato de prestación de servicio público, sujeto a las normas de Derecho administrativo. De esta forma, la complejidad en la organización del ELEAM ha dado lugar a una confluencia de normas. De hecho, estos establecimientos son objeto de regulación tanto del Derecho Público como Privado, y no solo del Derecho administrativo y Derecho civil y comercial, ya mencionados, sino también penal, tributario, laboral y constitucional, así como el emanado de los Tratados Internacionales de Derechos Humanos y de la normativa que regla el ejercicio de las profesiones liberales vinculadas a la atención de ancianos ${ }^{69}$.

Además, según el ámbito de actuación, estos establecimientos podrán ser locales o municipales, provinciales, nacionales o regionales. $\mathrm{Y}$, conforme a la actividad realizada, podrán ser residencias gerontológicas, es decir, destinadas a otorgar alojamiento a cambio del pago de este servicio; asilos y hogares, que tienen un objetivo similar al de las residencias gerontológicas pero que, técnicamente, son gratuitos y están destinados a personas indigentes; hospitales geriátricos, en los que los ancianos tienen derecho a casa y comida y también a atención sanitaria permanente; y, finalmente, los centros de día, que otorgan al anciano un espacio donde habitar durante el día ${ }^{70}$.

En cuanto a su configuración jurídica, la doctrina no pasa de referirse a la calificación contractual de los ancianos internados en ELEAM como un contrato atípico o innominado, similar al contrato de hospedaje ${ }^{71}$, en circunstancias de que se trata de un instituto jurídico polimórfico: como ya hemos dicho, en su configuración concurren simultáneamente normas de Derecho público y de Derecho privado, generándose diversas relaciones jurídicas dependiendo de los sujetos intervinientes; en suma, como se ha señalado, se trata de un servicio social de carácter contractual ${ }^{72} \mathrm{y}$, por ende, existe un derecho de ingreso y retiro del anciano y un derecho de admisión y alta del establecimiento ${ }^{73}$.

Si bien el carácter contractual de la internación tiene sus antecedentes más remotos entre los siglos VIII y XII, históricamente, el proceso de institucionalización del anciano presenta las siguientes etapas: el retiro medieval, los hospitales-asilos de la

\footnotetext{
${ }^{69}$ Dabove (2005a) p. 53.

70 Dabove (2005) p. 220.

${ }^{71}$ En él concurren diversas figuras contractuales, como el contrato de arrendamiento de la habitación, de servicio para las prestaciones médicas y de obra para la comida. GALVÁN GALLEGOS (2001) p. 1025. Ello explica la multiplicidad de categorizaciones que ha recibido. Así, por ejemplo, en España, la Ley extremeña 2/1994 de asistencia social geriátrica de 28 de abril, se refiere a esta figura jurídica como contrato de hospedaje (artículo 25); en cambio, Kemelmajer De CARLUCCI lo define como un contrato atípico, bilateral, de tracto sucesivo y de cambio y no de simple hospedaje (cfr. KeMELMAJER (2006 p. 59). Citando una sentencia argentina, la autora señala que "la prestación de servicios de geriatría importa una relación contractual atípica que involucra un conjunto de servicios, que trascienden al simple suministro de alojamiento y alimentación, incluyendo también el cuidado, la vigilancia y la prestación médica convenida. Por ello, no puede asimilarse al simple hospedaje. Por otro lado, dado que la actividad del instituto geriátrico está organizada como empresa, se trata de una relación de tipo comercial”. A las cercanías y diferencias entre este contrato atípico y los contratos de locación de servicios y hospedaje se refieren FRUSTAGLI y HERNÁNDEZ (2005) pp. 81 y 82.

72 Dabove (2005a) p. 53.

${ }^{73}$ En este sentido, DABOVE (2000) p. 229, señala que deben primar los derechos del internado sobre los del establecimiento toda vez que lo que está en juego es el ejercicio legítimo de la libertad de un sujeto.
} 
modernidad y los hogares-hospitales de las sociedades de beneficencia que empiezan a difundirse en el siglo XIX ${ }^{74}$. En efecto, los antecedentes más remotos de los hogares de ancianos datan de comienzos de la Edad Media (siglo VI), a los cuales accedían las personas más adineradas con el objeto de recluirse espiritualmente durante esta última etapa de la vida. En la Edad Moderna encontramos el antecedente directo de las actuales residencias para ancianos; se trata de los hospicios/asilos o alms house para ancianos y desvalidos, que pasan a ser una de las tres categorías de viviendas institucionalizadas para mendigos ${ }^{75}$. Por último, durante la Edad Contemporánea, a través de las sociedades de beneficencia del siglo XIX, se consolidan sistemas formalizados de ayuda privada que incentivarán la construcción de hogares y hospitales para la protección de indigentes, entre ellos, los ancianos. A partir de los años setenta, los hogares de ancianos proliferan de forma tal que constituyen la respuesta más adecuada para afrontar las necesidades ordinarias como de asistencia sanitaria.

En todo caso, y sin perjuicio de que el vínculo generado entre el particular y el ELEAM es de naturaleza contractual, es posible también sostener que estos son verdaderos servicios sociales, toda vez que cumplen un fin público que interesa a la sociedad toda, de ahí el control en su constitución y la fiscalización a la que están sujetos, incluso cuando el capital que lo crea proviene absolutamente de manos privadas. Así las cosas, se trataría de un servicio social particular, por su carácter contractual respecto de las partes vinculadas con su funcionamiento ${ }^{76}$.

Actualmente, los ELEAM han proliferado de tal forma, que han pasado a sustituir a las familias en el cuidado de sus miembros más ancianos, fenómeno que se intensifica con el fortalecimiento del sector terciario de la producción que ha visto en esta necesidad social un negocio rentable: los servicios geriátricos.

Se calcula que en Chile existen 663 ELEAM, con una cifra que supera los 13 mil adultos mayores residentes ${ }^{77}$. Además, puede afirmarse que se trata de instituciones de tamaño pequeño y que, en aproximadamente el 75\% de ellos, el número de residentes alcanza las 28 personas. Asimismo, en estos establecimientos se observa una mayor presencia de adultos mayores (casi la mitad) que padecen algún grado de dependencia, bien física o, en menor grado, psicológica ${ }^{78}$, cuestión que incide, entre otras cosas, en el costo del ELEAM: a mayor dependencia, mayor costo.

Confrontando estos datos con la dotación de los ELEAM, resulta que menos de la mitad de ellos están capacitados para atender personas con estos tres tipos de valencia;

\footnotetext{
${ }^{74}$ Así lo señala DABOve (2000) pp. 208 y ss.

75 Las otras dos son las house of correction o work-house, para los mendigos aptos para el trabajo, y las casas cuna o asilos para niños mendigos. DABOVE (2000) p. 211.

76 Así lo afirma DABOve (2005a) p. 54.

77 Servicio Nacional Del Adulto Mayor (2008) pp. 27 y 46. La cifra relativa a las más de 13 mil adultos mayores residentes, corresponde a las 530 residencias que fueron objeto de dicho estudio.

${ }^{78}$ Los adultos mayores en ELEAM que siguen a esta cifra son las autovalentes y, en tercer término, las personas con un nivel de autonomía reducido, es decir, las personas que se encuentran postradas que requieren una atención más especializada y continua. SERVICIO NACIONAL Del AdulTo MaYOR (2008) p. 46.
} 
luego le siguen los ELEAM que asisten a personas autovalentes y dependientes y, por último, un reducidísimo número de establecimientos reciben exclusivamente a adultos mayores postrados ${ }^{79}$.

\section{PROTECCIÓN JURÍDICA INTERNACIONAL DE LOS ADULTOS MAYORES}

Desde hace décadas, el Derecho Internacional ha considerado al anciano como especial sujeto de protección. Así, los derechos de los adultos mayores están consagrados en diversas Declaraciones, Pactos y Tratados Internacionales. Revisemos algunos de ellos.

La Declaración Universal de Derechos Humanos de 1948 se refiere ya, incipientemente, a la ancianidad, al señalar que toda persona tiene derecho a los seguros en caso de vejez u otros casos de pérdida de sus medios de subsistencia por circunstancias independientes de su voluntad (artículo 25.1).

Por su parte, y más específicamente, los Principios de las Naciones Unidas en favor de las Personas de Edad (1991), refiriéndose al principio de la Independencia, garantizan el derecho que tiene la persona de edad a residir en su propio domicilio por tanto tiempo como sea posible. Agregan que las personas de edad deberán poder disfrutar de los cuidados y la protección de la familia y la comunidad de conformidad con el sistema de valores culturales de cada sociedad. Y, más concretamente, señalan que las personas de edad deberán poder disfrutar de sus derechos humanos y libertades fundamentales cuando residan en hogares o instituciones donde se les brinden cuidados o tratamiento, con pleno respeto de su dignidad, creencias, necesidades e intimidad, así como de su derecho a adoptar decisiones sobre su cuidado y sobre la calidad de su vida ${ }^{80}$.

A su vez, en el sistema interamericano de Derechos Humanos, el artículo 16 de la Convención Americana sobre Derechos Humanos, conocida como Pacto de San José de Costa Rica (1969), señala que toda persona tiene derecho a la seguridad social que le proteja contra las consecuencias de la desocupación, de la vejez y de la incapacidad que, proveniente de cualquier otra causa ajena a su voluntad, le imposibilite física o mentalmente para obtener los medios de subsistencia.

\footnotetext{
${ }^{79}$ El artículo 11 del Reglamento de Establecimientos de Larga Estadía para Adultos Mayores establece que se entenderá por adulto mayor autovalente aquel que realiza, sin necesidad de ayuda, las actividades de la vida diaria de bañarse, vestirse, usar el inodoro, trasladarse, mantener la continencia y alimentarse. Por adulto mayor dependiente se entiende aquel que requiere ayuda para realizar algunas de las actividades señaladas o, en caso de dependencia psíquica, presenta trastornos conductuales tales como: fugas, agresiones verbales o físicas, deambulación sin propósito, etc. En tercer término, adulto mayor postrado es aquel que está totalmente incapacitado para realizar las actividades señaladas.

80 Asimismo, el Artículo 11 apartado a) de la Declaración sobre el Progreso y el Desarrollo en lo Social, proclamada por la Asamblea General de las Naciones Unidas (Resolución 2542 (XXIV), de 11 de diciembre de 1969) plantea que el progreso y el desarrollo en lo social deben encaminarse a la provisión de sistemas amplios de seguridad social y los servicios de asistencia social y el establecimiento y la mejora de sistemas de servicios y seguros sociales para todas aquellas personas que por vejez no puedan ganarse la vida, temporal o permanentemente, teniendo en cuenta la necesidad de garantizar el debido nivel de vida a estas personas, a sus familias y a quienes están a su cargo.
} 
El Protocolo Adicional a la Convención Americana sobre Derechos Humanos en materia de derechos económicos, sociales y culturales, conocido como "Protocolo de San Salvador" (1988), contiene medidas específicas encaminadas a lograr la "Protección de los Ancianos", a que se refiere su artículo 17. Esta norma establece que toda persona tiene derecho a protección especial durante su ancianidad y que los Estados partes se comprometen a adoptar de manera progresiva las medidas necesarias a fin de llevar este derecho a la práctica y en particular a:

a. proporcionar instalaciones adecuadas, así como alimentación y atención médica especializada a las personas de edad avanzada que carezcan de ella y no se encuentren en condiciones de proporcionársela por sí mismas;

b. ejecutar programas laborales específicos destinados a conceder a los ancianos la posibilidad de realizar una actividad productiva adecuada a sus capacidades respetando su vocación o deseos;

c. estimular la formación de organizaciones sociales destinadas a mejorar la calidad de vida de los ancianos.

Asimismo, no pocas Recomendaciones, Observaciones, Asambleas y Conferencias desarrolladas a nivel internacional, consagran los derechos de los adultos mayores conforme a sus intereses, necesidades y condiciones de vida particulares.

En este ámbito, destaca la Primera Asamblea Mundial sobre el Envejecimiento que, celebrada en Viena en 1982, adoptó el Plan de Acción Internacional sobre el Envejecimiento, documento que reúne un conjunto de sesenta medidas en materias de carácter sociosanitario relacionadas con la vejez, pero que, lamentablemente, no se refirió al maltrato ${ }^{81}$.

En efecto, solo posteriormente, el II Plan de Acción Internacional sobre el Envejecimiento, adoptado en la Segunda Asamblea Mundial sobre el Envejecimiento el año 2002 en Madrid, se refiere, por primera vez, al maltrato ejercido contra el adulto mayor. En él se señala que el proceso de envejecimiento entraña la reducción de la capacidad de recuperarse, razón por la que las personas de edad que han sido víctimas de malos tratos, pueden no llegar a recobrarse nunca totalmente, sea física como emocionalmente, de la experiencia sufrida. Se agrega, además, que el efecto de la experiencia traumática puede verse agravado por el hecho de que la vergüenza y el miedo producen una renuencia a pedir ayuda. Se señala que las comunidades deben trabajar unidas para prevenir los malos tratos, el fraude al consumidor y los delitos contra las personas de edad. En este sentido, se afirma que es necesario que los profesionales reconozcan los riesgos de abandono, maltrato o violencia que pueden presentar los encargados de atender a las personas de edad en el hogar o en contextos comunitarios o institucionales.

Dentro de las medidas para la eliminación de todas las formas de abandono, abuso y violencia contra las personas de edad, este Plan establece a) Sensibilizar a los

${ }^{81}$ En el año 1992, la Asamblea General de Naciones Unidas aprobó la Proclamación sobre el Envejecimiento, que establece las orientaciones generales para seguir aplicando el Plan de Acción Internacional sobre el Envejecimiento y que establece el año 1999 como el Año Internacional de las Personas de Edad. 
profesionales y educar al público en general, valiéndose de los medios de difusión y campañas de concienciación sobre los abusos contra las personas de edad y sus diversas características y causas; b) Abolir los ritos de viudez que atentan contra la salud y el bienestar de las mujeres; c) Promulgar leyes y establecer medidas legales para eliminar los abusos contra las personas de edad; d) Eliminar las prácticas nocivas tradicionales que afectan a las personas de edad; e) Promover la cooperación entre el gobierno y la sociedad civil, incluidas las organizaciones no gubernamentales, para hacer frente al maltrato de las personas de edad, desarrollando, entre otras cosas, iniciativas comunitaria; f) Reducir al mínimo los riesgos que entrañan para las mujeres de edad todas las formas de abandono, maltrato y violencia, creando en el público mayor conciencia de esos fenómenos, y protegiéndolas de ellos, especialmente en situaciones de emergencia; g) Alentar a que se sigan investigando más amplia de las causas, naturaleza, magnitud, gravedad y consecuencias de todas las formas de violencia contra las mujeres y los hombres de edad y dar amplia difusión a las conclusiones de las investigaciones y estudios.

Asimismo, el Plan prevé la creación de servicios de apoyo para atender a los casos de abuso y maltrato. En este sentido, se señalan las siguientes medidas: a) Establecer servicios para las víctimas de malos tratos y procedimientos de rehabilitación para quienes los cometen; b) Alentar a los profesionales de la salud y de servicios sociales y al público en general a que informen sobre los casos en que se sospeche la existencia de malos tratos a personas de edad; c) Alentar a los profesionales de la salud y de servicios sociales a que informen a las personas de edad que puedan haber recibido malos tratos, sobre la protección y apoyo de que disponen; d) Incluir en la capacitación de las profesiones asistenciales la forma de encarar los casos de maltrato a las personas de edad; e) Establecer programas de información para prevenir a las personas de edad del fraude contra los consumidores.

En la Conferencia de Madrid donde se acodó este II Plan Acción Internacional sobre el Envejecimiento, se otorgó un mandato a las Comisiones Regionales con el objeto de trasladar dicho Plan a programas de acción regionales. De esta forma, se celebró, en noviembre de 2003, en Santiago de Chile, la Conferencia Regional Intergubernamental sobre Envejecimiento, que culminó con la adopción de una Estrategia regional de implementación para América Latina y el Caribe del Plan de Acción Internacional de Madrid.

En cuanto al ámbito europeo, en el marco del Consejo de Europa, cabe destacar la Carta Social Europea de 1961 y el Protocolo Adicional de 1988, que incluye un artículo referido específicamente a la protección de los adultos mayores ${ }^{82}$. Por su parte, en el

\footnotetext{
82 Artículo 4. Derecho a protección social de las personas ancianas.

Con el fin de garantizar el ejercicio efectivo del derecho a protección social de las personas ancianas, las Partes se comprometen a tomar o promover, directamente o en cooperación con organizaciones públicas o privadas, las medidas adecuadas encaminadas, en particular:

1. A permitir a las personas ancianas seguir siendo, durante el mayor tiempo posible, miembros de pleno derecho de la sociedad mediante:

a. Recursos suficientes que les permitan llevar una existencia decorosa y desempeñar un papel activo en la vida pública, social y cultural;
} 
marco del Derecho Comunitario, específicamente del Parlamento Europeo, ha emanado la Resolución de 18 de febrero de 1982, acerca de la situación y los problemas de las personas de edad avanzada en la Comunidad Europea y, más recientemente, la Resolución de 14 de marzo de 1994, sobre medidas legislativas en materia de ancianidad. Desde el Consejo de las Comunidades cabe destacar la Decisión 93/512, de 21 de septiembre de 1993, relativa a la puesta en marcha del programa Iniciativa Tecnológica Comunitaria para los Ancianos y Personas con Discapacidades (TIDE). Asimismo, en la Declaración de Principios del Consejo de la Unión Europea y de los Ministros de Asuntos Sociales, de 6 de diciembre de 1993, se declara la plena ciudadanía de personas de edad avanzada en cuanto a libertad e igualdad de derechos y deberes en todos los ámbitos de la vida social, se proclama la lucha contra la exclusión y el aislamiento social y se establece como principio fundamental de esta política comunitaria, el de la solidaridad entre generaciones (artículo 9.1).

\section{NECESIDAD DE UN MARCO NACIONAL DE PROTECCIÓN JURÍDICA DE LOS ADULTOS MAYORES}

La principal crítica surgida en la doctrina extranjera frente a la positivización de la protección del adulto mayor, es que si bien el Derecho Internacional se refiere específicamente a ella, reconociendo a la ancianidad diversos derechos de carácter económico, social y cultural, lamentablemente, estos tienen limitada eficacia interna ${ }^{83}$. En este sentido, se ha señalado que se trata de derechos de reciente consagración y que, en el mejor de los casos, han dado lugar a la creación de políticas sociales coyunturales y no de derechos subjetivos directamente operativos ${ }^{84}$. Por otra parte, en esta materia, el Derecho internacional ha sido objeto de un escaso desarrollo a nivel interno y, cuando este existe, no logra generar un estatuto orgánico, situación que origina cierto caos normativo.

En efecto, la Observación General número 6 de 1995, formulada por el Comité de Derechos Económicos, Sociales y Culturales ${ }^{85}$-que es el órgano encargado de supervisar la aplicación del Pacto Internacional de Derechos Económicos, Sociales y Culturales-

b. La difusión de informaciones relativas a las facilidades y servicios de que disponen las personas ancianas y sus oportunidades de aprovecharlos.

2. A permitir a las personas ancianas escoger libremente su modo de vida y llevar una vida independiente en su entorno habitual durante todo el tiempo que lo deseen y que sea posible, mediante:

a. La posibilidad de disponer de viviendas apropiadas a sus necesidades y estado de salud o de ayudas adecuadas para el acondicionamiento de la vivienda;

b. La asistencia sanitaria y los servicios que su estado requiera.

3. A garantizar a las personas ancianas que viven en instituciones, la asistencia apropiada dentro del respeto a su vida privada, y su participación en la determinación de las condiciones de vida dentro de dichas instituciones.

83 Kemelmajer (2006) p. 43.

${ }^{84} \mathrm{Al}$ respecto, Dabove (2005) p. 448 y STANZIOne (2007) p. 60.

85 Observación General núm. 6. Los derechos económicos, sociales y culturales de las personas mayores: 8/12/95 (puntos 11, 12, 14 y 15). 
pone de manifiesto ciertas falencias en lo que se refiere a la protección de los adultos mayores. Esta Observación señala que si bien ni este Pacto ni en la Declaración Universal de Derechos Humanos se hace explícitamente referencia a la edad como factor prohibido de discriminación -omisión que se explica porque el problema del envejecimiento de la población no era tan evidente o tan urgente al momento de la adopción de estos instrumentos-, dicho factor podría quedar implícito en la prohibición de discriminación por "condición social". Se agrega que en los Informes emitidos por los Estados hasta esa fecha no se habían recogido sistemáticamente datos sobre la situación de los adultos mayores, salvo en lo relativo al derecho a la seguridad social, de manera que debía insistirse en que en ellos se tratara de manera más adecuada la situación de los ancianos en relación con cada uno de los derechos reconocidos en el Pacto.

Lamentablemente, Chile no hace excepción a esta realidad. Lo cierto es que la doctrina jurídica chilena no ha tocado mayormente estas temáticas, realidad que contrasta con algunos países vecinos como Argentina y, por cierto, con la realidad europea, donde desde hace ya varios años se tiende a la creación de un estatuto específico, pretensión focalizada no solo en crear un marco jurídico adecuado sino en integrar políticas económicas, sociales, científicas, sanitarias, culturales, y de toda índole, en beneficio de los adultos mayores.

En efecto, ordenamientos como el español y el argentino reconocen rango constitucional a la protección de la denominada "Tercera Edad"86, siguiendo así la carta de navegación determinada por el Derecho Internacional de los Derechos Humanos, que, como hemos analizado, avanza decididamente hacia una protección progresiva de los derechos de los ancianos.

En el contexto nacional, los esfuerzos por fortalecer ciertas prestaciones sociales básicas, como el acceso a la salud y el reforzamiento del régimen de jubilación y pensión ${ }^{87}$, son indispensables y elogiables, pero aún insuficientes frente a la envergadura de la desregulación existente en materia de protección jurídica de la ancianidad.

${ }^{86} \mathrm{La}$ Constitución argentina menciona a los ancianos como especiales sujetos de protección en su artículo 75 inciso 23: "Corresponde al Congreso: (...) legislar y promover medidas de acción positiva que garanticen la igualdad real de oportunidades y de trato y el pleno goce de los derechos reconocidos por esta Constitución y los Tratados Internacionales vigentes sobre Derechos Humanos, en particular respecto de los niños, las mujeres, los ancianos y las personas con discapacidad". Por su parte, el artículo 50 de la Constitución Política española realiza una referencia específica a los adultos mayores al señalar que "los poderes públicos garantizarán, mediante pensiones adecuadas y periódicamente actualizadas, la suficiencia económica a los ciudadanos durante la tercera edad. Asimismo, con independencia de las obligaciones familiares, promoverán su bienestar mediante un sistema de servicios sociales que atenderá a sus problemas especificos de salud, vivienda, cultura y ocio".

87 Con anterioridad a 1980 existía en Chile un sistema de pensiones que hoy administra el Instituto de Normalización Previsional (INP). Como es sabido, en el año 1981, se crea el sistema previsional de ahorro individual, bajo la gestión de las Administradoras de Fondos de Pensiones (AFP). Posteriormente, diversas leyes van otorgando beneficios previsionales, entre otras, la Ley 19.234 de 1993, que establece a favor de las personas exoneradas por razones políticas en el período 1973-1990, abonos de tiempo, pensiones no contributivas y el derecho a cobro de desahucio; la Ley No 19.350 de 1994, relativa a las Pensiones Asistenciales (PASIS), estableciendo su carácter vitalicio; la Ley No 19.404, de 1995, que determina una rebaja de edad para pensionarse, considerando la realización de trabajos pesados, extendiendo esta rebaja a todas las cajas del antiguo sistema; y la Ley No 19.539, de 1998, que incorpora a los pensionados a las Cajas de Compensación de Asignaciones Familiares, instituciones de seguridad social que cumplen funcio- 
En efecto, en el año 1995, al crearse la Comisión Nacional para el Adulto Mayor ${ }^{88}$ y el Comité Nacional para el Adulto Mayor, dependiente del Ministerio Secretaría General de la Presidencia ${ }^{89}$, comenzó a forjarse cierta institucionalidad a favor de la ancianidad, no obstante lo cual, aún no nos acercamos a un estatuto medianamente orgánico en la materia.

Más tarde, en septiembre del año 2002, se promulgó la Ley 19.828 que crea el Servicio Nacional del Adulto Mayor (SENAMA), el cual inicia sus funciones en enero del año 2003, con el objetivo de velar por la plena integración del adulto mayor en la sociedad, protegerlo del abandono y la indigencia, defender los derechos que la Constitución y las leyes le reconocen, y luchar por la no discriminación y marginación de los adultos mayores.

Poco después, en enero de 2004, fue creado el Comité de Ministros del Adulto Mayor -conformado por los ministros de los gabinetes sociales-, en cuyo marco se desarrolla el Plan Nacional Conjunto que, en la actualidad, agrupa a diversas instituciones, públicas y privadas, comprometidas con acciones para los adultos mayores, a fin de traducir en hechos concretos las políticas nacionales en beneficio del adulto mayor. Así, la oferta pública de la última década se ha desarrollado a través de diversas iniciativas sectoriales y multisectoriales, dirigidas al conjunto de este sector de la población (la llamada cobertura universal), o bien, a grupos especialmente carenciados (la denominada cobertura selectiva).

En cuanto al maltrato, si bien en términos mediáticos algunos casos paradigmáticos denunciados han contribuido a visibilizar el abandono de miles de adultos mayores en nuestro país, lo cierto es que la protección jurídica de estas personas es todavía extremadamente precaria frente a estos abusos.

La complejidad del fenómeno del maltrato contra el adulto mayor dificulta la configuración de un marco jurídico adecuado. En efecto, las causas que provocan este abuso son difíciles de determinar y, como suele suceder en las situaciones de violencia sostenida, la identificación del agresor es difícil, entre otras razones, porque las víctimas desconocen sus derechos y la normativa que los protege, y no se atreven a denunciar. Esto genera un círculo de violencia que, como es fácil colegir, agudiza la situación de indefensión e invisibiliza aun más la vulneración que se está produciendo.

Así, para prevenir y sancionar este tipo de violencia en el ámbito familiar, se tramita actualmente en el Congreso un proyecto de ley que pretende incluir, explícitamente, al adulto mayor como sujeto vulnerable específico en la Ley No 20.066 sobre Violencia Intrafamiliar, aumentar la protección penal en casos de abuso patrimonial

nes de un Servicio de Bienestar. Recientemente, la Ley 20.255, de marzo de 2008, introdujo una reforma sustancial al sistema previsional chileno, previendo, entre otras mejoras, una Pensión Básica Solidaria de Vejez para los adultos mayores de 65 años que no tengan derecho a pensión de algún régimen previsional y se encuentren dentro de la población de menores ingresos. Además, esta ley estableció un Aporte Previsional Solidario de Vejez consistente en un aporte estatal a aquellos adultos mayores que reciban una pensión inferior a la Pensión Máxima con Aporte Solidario.

${ }^{88}$ Decreto Supremo No 27.

${ }^{89}$ Decreto Supremo No 203-95. 
contra ancianos, y especificar una medida de protección especial para situaciones de adultos mayores abandonados ${ }^{90}$.

En cuanto al maltrato de carácter institucional se advierten también importantes falencias y una ausencia casi total de facultades de fiscalización por parte de organismos especializados. En efecto, el único instrumento en este ámbito es el Reglamento de Establecimientos de Larga Estadía para Adultos Mayores, al que ya nos hemos referido. Este Reglamento señala que la instalación y funcionamiento de los ELEAM está sujeta a la autorización de la respectiva Secretaría Regional Ministerial de Salud, a la que le corresponde la fiscalización, control y supervisión de estas instituciones y que debe aplicar las disposiciones del Libro X del Código Sanitario al momento de establecer las sanciones pertinentes ${ }^{91}$. Asimismo, este Reglamento enuncia los requisitos para obtener dicha autorización; se refiere a las condiciones físicas mínimas del local -haciendo aplicables la normativa contenida en el Reglamento de Hoteles y Establecimientos Similares $^{92-}$; y a las exigencias mínimas profesionales respecto de la dirección técnica y del personal.

Sin embargo, sería deseable que una ley, y no un reglamento, regulara estas cuestiones. Como se ha señalado, los decretos reglamentarios no tienen el mismo alcance jurídico-político que las leyes generales, ni garantizan con fuerza los derechos subjetivos; además, pueden ser reemplazados fácilmente por la voluntad del gobierno de turno de acuerdo con las circunstancias concurrentes y a las políticas sociales impulsadas en un determinado periodo, con la consiguiente inseguridad jurídica que ello conlleva ${ }^{93}$.

Con todo, es evidente la necesidad de elaborar un sistema nacional, orgánico, regularizado y estandarizado de los ELEAM, en el que se establezcan claramente las condiciones mínimas de funcionamiento y su adecuada fiscalización. Asimismo, es sumamente aconsejable que el estatuto que rija a estos establecimientos sea adecuadamente difundido, de manera que la sociedad toda, los familiares y, especialmente, el propio adulto mayor, pueda tomar una decisión informada en lo que respecta al ingreso a estas instituciones.

Se trata de un desafío no menor pues se debe construir un marco jurídico en el que, necesariamente, confluyen aspectos de carácter público, que están dados por la naturaleza de los fines que deben cumplir estos establecimientos, y de orden privado, dado que la mayoría de los ELEAM están constituidos con capital de particulares y a sus dependencias se ingresa mediante la suscripción de un contrato entre el establecimiento y el propio adulto mayor o, en su defecto, con su representante.

\footnotetext{
90 Nos referimos al proyecto de ley correspondiente a los Boletines refundidos Nos 5376-18, 5142-18, 5055-18, 4691-18, 4167-18, que se encuentra en el Senado en segundo trámite constitucional.

91 El artículo 147 del Código Sanitario establece la sanción de multa de un décimo de unidad tributaria mensual hasta mil unidades tributarias mensuales, la clausura de establecimientos, edificios, casas, locales, lugares de trabajo donde se cometiere la infracción; la cancelación de la autorización de funcionamiento o de los permisos concedidos; la paralización de obras; y el comiso, destrucción y desnaturalización de productos, cuando proceda.

92 Decreto 194 de 1978, del Ministerio de Salud.

${ }^{93}$ Así lo afirma Dabove (2000) p. 225 y (2005a) p. 53.
} 
En efecto, la primera cuestión que debe normalizarse es la internación misma en el ELEAM. En este sentido, cabe destacar que el anciano no pierde, por el hecho de su edad, la capacidad de contratar, de manera que es él quien debe prestar su consentimiento al momento de ingresar al establecimiento.

De hecho, el contrato de prestación de servicios es un acto mixto en el sentido que le da la Ley 19.496, de protección al consumidor ${ }^{94}$. En primer lugar, porque el adulto mayor tiene la calidad de consumidor al ser el destinatario final de los servicios comprometidos, sea como contratante directo o como beneficiario y, como tal, tiene los mismos derechos de las personas que contratan otros servicios; y, en segundo lugar, porque el ELEAM actúa indiscutiblemente como proveedor de servicios, cobrando por ello un precio determinado.

Pues bien, considerando lo anterior, cabe la posibilidad de que sea el mismo adulto mayor quien contrate el servicio; que lo haga algún integrante de la familia, ya sea en calidad de representante si ha mediado nombramiento de curador del demente, o bien, en virtud de una estipulación a favor de este ${ }^{95}$; y, por último, que lo haga un tercero ajeno, respetando, en todo caso, la exigencia de consentimiento por parte del adulto mayor en lo que respecta a la internación.

Lejos de estas situaciones, puede suceder más bien que, figurando el anciano como parte que contrata directamente con el establecimiento, sean los propios familiares o personas cercanas quienes adoptan esta decisión o inducen, ilegítimamente, al anciano a tomarla, de manera que, en estos casos, no existe consentimiento o este nace viciado y, por ende, no se ha contratado válidamente.

La primera preocupación, en consecuencia, debiera ser la regulación y debido control de los contratos que se firman con estas instituciones, sobre todo si consideramos que, muchas veces, el ingreso del anciano al establecimiento es hasta el final de sus días.

Por lo anterior, a nuestro juicio, la legislación debiera exigir que el consentimiento de la persona mayor que ingresa a un establecimiento de larga estadía conste de manera fehaciente, requiriéndose la autorización judicial en los casos en que el anciano presente algún tipo de incapacidad. Además, debiera prohibirse su permanencia en la institución si la persona mayor se opone, salvo, por supuesto, que medie una autorización judicial que así lo consienta.

En este sentido, cabe señalar que en España, producto de las internaciones forzadas de ancianos a instituciones de larga estadía, la Fiscalía General del Estado, mediante

\footnotetext{
${ }^{94}$ El artículo 2 de la Ley 19.496 establece que "Quedan sujetos a las disposiciones de esta ley: a) Los actos jurídicos que, de conformidad a lo preceptuado en el Código de Comercio u otras disposiciones legales, tengan el carácter de mercantiles para el proveedor y civiles para el consumidor". A la calidad del contrato de prestación de servicio como negocio de consumo se refieren FRUSTAGLI y HERNÁNDEZ (2005) pp. 82 y 85. Al respecto, la particular condición de vulnerabilidad de algunos adultos mayores ha propiciado la búsqueda de soluciones normativas tendientes a reforzar la protección de este grupo. Así, existe un proyecto de ley presentado en octubre del año 2007, que busca modificar la Ley 19.496, estableciendo beneficios para la tercera edad en lo relativo a la forma de pago de ciertas ofertas y promociones comerciales (Boletín 5390-03).

95 En Argentina se ha reconocido jurisprudencialmente esta figura jurídica como constitutiva de este contrato. Frustagli y Hernández (2005) pp. 81 y 82.
} 
Instrucción 3/1990 relativa al "Régimen Jurídico que debe regir para el ingreso de personas en Residencias de la tercera edad”, señaló que el internamiento debe realizarse con el consentimiento del titular del bien jurídico, siempre que se manifieste como expresión de una voluntad libre y consciente, pues es el propio anciano quien contrata el centro, las condiciones y los servicios a prestar por ese centro durante el periodo de su internamiento. Esta Instrucción agrega que en caso de enfermedad o deficiencia física o psíquica debe recabarse preceptivamente la autorización judicial para proceder a la internación. Y si el deterioro físico o mental se produce con posterioridad al momento que tuvo lugar el internamiento, debe ser comunicado por el establecimiento a la autoridad judicial para que dicte la correspondiente autorización ${ }^{96}$.

En efecto, la doctrina de este país ha señalado que el internamiento forzoso autorizado no es un medio de protección social sino una privación de libertad autorizada o bien convalidada judicialmente con el objeto de aplicar una terapia siquiátrica sobre una persona afectada por trastorno psíquico, cuando esta carece de capacidad para decidir su conveniencia y exista grave riesgo para su salud. Ello explica la ilegalidad de los internamientos de ancianos en centros geriátricos a instancias de sus familiares cuando aquellos tienen facultades intelectivas y volitivas y se oponen a dicho ingreso, razón por la cual estos familiares y los responsables de dichos centros que incurren en estas conductas, pueden llegar a cometer el delito de detenciones ilegales ${ }^{97}$.

El segundo ámbito que debe abordarse es la estructura y dotación de los Establecimientos de Larga Estadía.

$\mathrm{Al}$ respecto, se ha dicho que este tipo de instituciones responden a un orden de repartos vertical, a un sistema organizado de vida en función de una idea eje. En este sentido, los problemas medulares que deben resolverse son los denominados "criterios de repartos", esto es, el sostenimiento de determinados criterios y objetivos de actuación, y la configuración de los "supremos repartidores", es decir, la determinación de las autoridades que materialicen lo anterior ${ }^{98}$.

Se trata de cuestiones de capital importancia pues inspiran y dirigen el funcionamiento del ELEAM. Son los principios rectores tanto de los administradores y empleados como de sus residentes. Por esta razón, debiera tratarse de un componente heterónomo y, nuevamente, modelado por la ley.

En este sentido, como ya lo hemos puesto de relieve, el Reglamento de Establecimientos de Larga Estadía para Adultos Mayores, que constituye el marco jurídico para la instalación y funcionamiento de este tipo de residencias, solo contempla una definición de ellas sin enunciar las directrices que deben inspirar su funcionamiento.

En tercer lugar, los ELEAM debieran estar sujetos a una fiscalización periódica a cargo de un equipo de inspección especializado, encargado de vigilar las condiciones mínimas de funcionamiento de estas instituciones, la calidad de los servicios prestados,

\footnotetext{
${ }^{96} \mathrm{El}$ artículo 763 de la Ley de Enjuiciamiento Civil española de 2000 se refiere al Internamiento no voluntario por razón de trastorno psíquico.

97 Chimeno Cano (2005) pp. 9-15.

${ }^{98}$ DABOVe (2000) p. 218.
} 
la cualificación profesional del personal que trabaja en ellas y, por cierto, la verificación de las condiciones de vida, médicas y sanitarias de los ancianos internos y la voluntad de permanencia de estos en el lugar.

A ello se han encaminado iniciativas aisladas que, lamentablemente, no han prosperado. Así, en el año 2004 se presentó al Parlamento un proyecto de ley que busca adecuar la Ley 19.828, creadora del Servicio Nacional del Adulto Mayor, confiriéndole atribuciones para que el actual registro voluntario de información relativo a los servicios que se prestan a los adultos mayores mantenga su voluntariedad respecto de todos los prestadores de servicios en general, salvo para las instituciones comprendidas en la expresión "hogares de larga estadía", cuyo registro pasaría a ser obligatorio ${ }^{99}$. Esta es una de las medidas más elementales que deben adoptarse para diseñar una adecuada labor de inspección. De hecho, en otros países se ha optado, incluso, por autorizar la fiscalización por parte de organizaciones de voluntarios, encargados de visitar periódicamente estas instituciones, desarrollando así, además, una importante labor social ${ }^{100}$.

Según señala Dabove ${ }^{101}$, una normativa nacional sobre residencias geriátricas debiera abordar los siguientes puntos centrales: a) debiera construirse considerando la vejez como un dato revelador del sistema jurídico, reforzando la igualdad ante la ley; b) garantizar el ejercicio de la libertad de los adultos mayores, especialmente, para evitar las internaciones no queridas; c) contemplar el respeto por el ejercicio del derecho a la salud del residente con el objeto de preservar su integridad y el goce de una vivienda digna; y d) asegurar el ejercicio del derecho de propiedad del internado ${ }^{102}$.

A modo de ejemplo, a nivel comunitario, el Consejo de Europa ha orientado a los países acerca de cuáles debieran ser las medidas a implementar frente a este problema en el ámbito jurídico ${ }^{103}$. En el año 1992 publicó un estudio denominado "La violence envers les personnes âgées" 104 , en el que reconoce el maltrato contra los mayores como un problema social creciente y oculto. El documento, que analizó la situación de 22 países europeos, aconseja la revisión de sus respectivos Códigos penales y civiles en lo que respecta a los adultos mayores, sus familiares y allegados. Recomienda institucionalizar acciones del ministerio público contra los agresores, entregar ayuda gratuita a las víctimas, desarrollar procesos extrajudiciales con testimonios de las víctimas (grabación sonora y visual, disposi-

${ }_{99}$ Nos referimos al proyecto contenido en el Boletín $\mathrm{N}^{\circ} 3582-18$.

100 MANTHORPE (2000) pp. 128-129.

101 DABOVE (2000) pp. 235-236.

102 En este último punto, cabe mencionar la prevención prevista en la ley andaluza frente a la comisión de delitos contra el patrimonio de los adultos mayores. Esta ley, bajo el título "Expoliación patrimonial", contiene una norma que establece que "Cuando las administraciones Públicas tengan noticia de que el patrimonio de una persona mayor está siendo objeto de expoliación, bien por sus propios familiares o por terceros, se procederá a comunicarle de forma expresa las acciones judiciales que pueden iniciar, proporcionándole asistencia jurídica si fuera necesario, sin perjuicio del traslado de tales hechos al Ministerio Fiscal" (Ley de Atención y Protección de Ancianos del Parlamento de Andalucía de 7 de julio de 1999, artículo 46).

103 El artículo 25 de la Carta Europea de Derechos Humanos de la Unión Europea establece que: "La Unión reconoce y respeta el derecho de las personas mayores a llevar una vida digna e independiente y a participar en la vida social y cultural".

104 Conseil De L’europe. Groupe D’étude Sur la Violence Envers Les Personnes Âgées (1992). 
ciones escritas, etc.), conceder a los tribunales el poder de investigar situaciones que engendren violencia, y ofrecer a los agresores la posibilidad de recibir tratamiento y ayuda psicológica. Por último, el estudio llamó a los países a incorporar en sus ordenamientos jurídicos la obligación de los profesionales de denunciar situaciones potenciales de maltrato a ancianos y de las cuales tomen conocimiento en el ejercicio de sus funciones.

A mayor abundamiento, en el año 2007, el Consejo de Europa aprobó la Recomendación 1796 referida a la situación de las personas mayores en Europa ("The situation of elderly persons in Europe"), en la que se señala que deben adoptarse medidas urgentes con el objeto de acabar con los "escándalos" en que se ven envueltas las casas de reposo y para evitar que las personas de edad sufran la exclusión social y vivan en condiciones inaceptables y contrarias a los principios fundamentales que rigen a los Estados miembros.

\section{EL SURGIMIENTO DE NUEVAS FIGURAS DE PROTECCIÓN}

Algunos de los mecanismos de protección del adulto mayor que suelen utilizarse en los ordenamientos jurídicos, sea en lo relativo a sus bienes como a su persona, son la tutela y curatela de adultos mayores incapacitados; la autotutela, es decir, la posibilidad de que la propia persona designe un guardador para casos de incapacidad futura ${ }^{105}$; la constitución de un fideicomiso para el supuesto de que el constituyente caiga en incapacidad, determinándose, en el evento de verificarse este supuesto, la transferencia de los bienes al fideicomisario nombrado ${ }^{106}$; la designación judicial de un administrador de apoyo $^{107}$; la formación especial de la validez de los poderes otorgados por personas incapacitadas y apoderamientos preventivos; las voluntades anticipadas; la regulación específica del consentimiento informado; el contrato de alimentos ${ }^{108}$; y, en el ámbito

105 La autodesignación del cargo tutelar ha sido recogida en España, en primer lugar, por el Código de Familia de Cataluña (artículo 172) y, posteriormente, en el Código Civil de dicho país, mediante Ley 41/ 2003, de 18 de noviembre, relativa a la protección patrimonial de las personas con discapacidad. En efecto, el párrafo segundo del artículo 223 del Código Civil español establece que "asimismo, cualquier persona con la capacidad de obrar suficiente, en previsión de ser incapacitada judicialmente en el futuro, podrá en documento público notarial adoptar cualquier disposición relativa a su propia persona o bienes, incluida la designación de tutor". El profesor ARCE FLOREZ-VALDÉS se refiere, in extenso, a un concepto más moderno de autotutela, esto es, a las denominadas declaraciones de "voluntades anticipadas", definiéndolas como un documento en el cual una persona mayor de edad con capacidad suficiente y libremente, expone las instrucciones que se deben tener en cuanta cuando se encuentre en una situación en las que las circunstancias que concurren no le permitan expresar personalmente su voluntad. ARCE FLóREZ-VALDÉS (2003) pp. 207-220, en especial, p. 208.

${ }^{106}$ Así lo propone WiLde (2003) p. 130.

107 Figura prevista en Italia mediante Ley 6/2004 de 9 de junio, y que consiste en que el juez tutelar del domicilio de una persona dependiente, le designa a esta otra encargada de asistirlo en las más variadas cuestiones, conservando la primera la capacidad de obrar para la celebración de aquellos actos que no requieran la representación exclusiva o asistencia necesaria de dicho administrador. Se refiere a ella, ZAMBRANO (2007) pp. 71-96.

108 LinaCero De La FUente (2004) p. 2262, lo define como un vínculo jurídico en donde no hay relación de parentesco entre alimentante y alimentario y por el cual una de las partes se obliga a proporcionar vivienda, manutención y asistencia de todo tipo a una persona durante su vida, a cambio de la transmisión de un capital en cualquier clase de bienes y derechos. 
penal, la agravación de las penas de ciertos delitos en caso de que el sujeto pasivo ofendido sea de edad avanzada.

Asimismo, se han construido nuevas y novedosas medidas. En España se ha propuesto la creación de una tutela o guarda automática por parte de los órganos de la Administración de los adultos mayores en situación de riesgo y desamparo -similar a la existente a favor de los menores ${ }^{109}$ - que autorice, por ejemplo, a separar al anciano del entorno en que vive; la creación de instituciones o figuras de protección del anciano, como el Letrado Defensor de Ausentes ${ }^{110}$; la mayor intervención de los respectivos órganos encargados de resguardar los intereses de las personas más vulnerables; la regulación de acciones que permitan hacer efectivo el derecho a la protección de la salud, como el resguardo de la autonomía del paciente, el consentimiento informado y la documentación clínica ${ }^{111}$; la estimulación del mercado de los seguros de dependencia ${ }^{112}$; y hasta la adopción legal de adultos mayores ${ }^{113}$.

En cuanto a la internación de los ancianos en establecimientos, se han ideado una serie de mecanismos alternativos, como las "situaciones convivenciales de ayuda mutua" que, organizadas mediante el denominado acogimiento familiar de adultos mayores, permiten que una familia idónea asuma, normalmente con carácter remunerado, el cuidado y atención de personas de edad avanzada. Esta figura existe en países como España ${ }^{114}$ y Francia ${ }^{115}$ y tiene, incluso, consecuencias de carácter sucesorio a favor de las personas acogedoras. Se ha regulado también el denominado "contrato asistencial", que prevé la legislación catalana, y que se celebra entre el órgano gestor del servicio, el usuario y, en su caso, las personas que se obliguen a efectuar las aportaciones para el pago del servicio. Este contrato requiere que los parientes que tienen la obligación de prestar alimentos al anciano que va a ser usuario de los servicios de la residencia, se comprometan al pago de dicho servicio, complementando o sustituyendo las aportaciones económicas del propio interesado. De esta forma, solo cuando estas prestaciones económicas familiares sean insuficientes o no existan, el costo del servicio lo asume el Estado ${ }^{116}$.

109 Regulada en el artículo 172 del Código Civil español.

110 Esta institución fue introducida en el principado de Asturias mediante Ley de 5 de abril de 1991 y regulada más tarde por la Ley $2 / 1998$ de 28 de noviembre.

111 LinaCero De La Fuente (2004) p. 2262.

112 CaSAdo Marín y López Y CaSASNOVAS (2001) pp. 208 y ss. cit. por RoCa (2003) p. 841.

113 ROCA (2003) p. 822.

${ }^{114}$ En España no existe tampoco una regulación orgánica y nacional en materia de protección jurídica de la ancianidad. La única ley local que constituye un marco jurídico completo en esta materia es la Ley de Atención y Protección de Ancianos del Parlamento de Andalucía de 7 de julio de 1999. En cuanto al sistema de acogimiento, si bien tampoco existe una regulación a nivel nacional, se han previsto diversas normativas al respecto, como la Ley 22/2000, de 29 de diciembre, de Acogida de Personas Mayores del Parlamento de Cataluña y la Ley 34/2002 de 10 de diciembre, de Acogida Familiar de Personas Mayores de Navarra.

115 Ley 89-475 de 10 de junio, relative à laccueil par des particuliers, a leur domicile, à titre onereux, de persones gées ou hadicapées adultes.

116 Nos referimos al Decreto 394/1996 de 12 de diciembre. A él se refiere RocA (2003) pp. 821-822. 
Todas estas son respuestas -ya implementadas o de lege ferenda- que surgen para satisfacer las necesidades de los adultos mayores, si bien, sin duda, ceden también en beneficio directo de las propias familias y de la sociedad toda. La diversidad de las materias de las cuales provienen nos da ciertas luces sobre la situación de carencia y desprotección en que este sector se encuentra.

\section{CONCLUSIONES}

El maltrato contra el adulto mayor constituye una lacra social tan grave como la violencia que se ejerce contra la mujer y los niños. Se presenta en todos los estratos sociales, raciales, étnicos, culturales y económicos, y constituye una manifestación clara de discriminación por razón de vejez.

En este sentido, la experiencia en la lucha contra la erradicación de la violencia intrafamiliar indica que las soluciones legales deben ir de la mano de la inyección de recursos que permitan crear una verdadera institucionalidad de apoyo a los ancianos, de promoción de derechos, de especialización y educación de los cuidadores y, muy especialmente, de la protección por parte de la familia.

Si bien en Chile no contamos con un marco adecuado de protección jurídica de la ancianidad, es posible advertir una mayor preocupación por fortalecer las políticas sociales que inciden en su favor, así como una creciente sensibilización frente al fenómeno del maltrato. Todo parece indicar que el camino por recorrer en la elaboración de un marco jurídico adecuado de protección, se dirige más bien al reforzamiento de ciertos aspectos legales parcelados que se relacionan con la ancianidad, como las reformas previstas en materia de violencia intrafamiliar, habiéndose descartado la creación de un estatuto orgánico de protección de la tercera edad.

Si esta es la opción político-legislativa, permítaseme señalar, a modo de contribución que, si conforme a dicha decisión es esencial detectar aquellas cuestiones en las que nuestros ancianos están sufriendo una mayor discriminación con el objeto de ponerles coto mediante una regulación especial, el maltrato progresivo que ellos están sufriendo requiere, sin ir más lejos, de una reforma integral urgente. Y no me refiero solo a modificaciones legales pues, a mi juicio, poco se avanza con el endurecimiento de penas y creación de delitos específicos. Es necesario capacitar a los cuidadores que trabajan en los establecimientos de larga estadía e implementar mecanismos de ayuda a los familiares que han asumido el cuidado doméstico de sus familiares más ancianos. Por ejemplo, a través de servicios domiciliarios (incluso voluntarios) que contribuyan a alivianar estas tareas con cierta periodicidad. De paso, así se previene, como hemos dicho, el círculo de la violencia. Además, sería aconsejable, tal como se está proponiendo respecto de la violencia contra la mujer, idear mecanismos de trabajo con víctimas y los propios agresores. Y, por cierto, establecer un sistema de registro adecuado y obligatorio de los establecimientos de larga estadía para adultos mayores con el objeto de levantar información periódica de carácter cuantitativo y cualitativo y realizar una eficaz y eficiente fiscalización.

En el ámbito propiamente jurídico, sería útil estudiar la implementación de algunas de las medidas que hemos reseñado anteriormente. La doctrina extranjera ha dado 
cuenta de que es necesario plasmar a nivel legal las normas internacionales de protección de la ancianidad a través de medidas específicas, aunque teniendo en cuenta que se trata de un problema complejo que quizá solo alcance solución mediante la evaluación global de cada persona mayor, desde la perspectiva por la que se distingue al anciano en vez de asimilarlo $^{117}$.

Estas medidas podrían ir, sin duda, desde la creación de una ley orgánica de protección de la tercera edad y previsión de medidas especiales de protección a, como propone Ciuro ${ }^{118}$ de forma ejemplar, la generalización de un derecho real de habitación del cónyuge supérstite en el hogar conyugal (sea cual fuere el valor de este y la cantidad de inmuebles dejados por el causante); la liberación de la posibilidad de testar sin respetar la legítima rigorosa para los ancianos que dejan de convivir con sus familias, ampliando las incapacidades para suceder; la reconsideración de las reglas que impulsan a jubilarse al llegar a una determinada edad; o la formación de instituciones educativas que haga realidad el ideal de la educación permanente.

Estos son algunos de los frentes que el legislador debe tener en cuenta al poner en marcha la opción de reforma legislativa que se ha planteado. Personalmente, desde el ámbito del Derecho civil, creo que sería pertinente revisar los mecanismos y procedimientos de incapacitación e incluir, en lo posible, alguna manifestación de la autotutela.

De lo dicho hasta acá podemos concluir que el envejecimiento sostenido de la población mundial y, en particular, el chileno, está abriendo nuevas perspectivas en diversas ciencias, no solo ligadas al ámbito biomédico donde, por cierto, los esfuerzos van encaminados, precisamente, a prolongar la vida humana, sino también en las pertenecientes a las áreas sociales y, en lo que a nosotros respecta, en el campo del Derecho.

La problemática del envejecimiento está mucho más presente en el ámbito jurídico de lo que, a primera vista, pudiera parecer. En este artículo nos hemos abocado a ciertos aspectos relativos al maltrato ejercido contra el adulto mayor $\mathrm{y}$, más específicamente, al maltrato institucional. Sin embargo, cabe destacar las repercusiones que este fenómeno acarrea en materia de alimentos legales, mecanismos y procesos de interdicción, el impacto en la rama del derecho sucesorio (como en la discusión relativa a la mayor o menor libertad de testar) y en diversas actividades contractuales (desde luego, el ingreso en establecimientos geriátricos).

Claramente, las responsabilidades son compartidas. A los propios ancianos les corresponde reivindicar progresivamente sus derechos y legítimas funciones al interior de la sociedad, a sus seres más cercanos les compete, desde luego, poner en práctica la solidaridad familiar, al Estado le cabe impulsar políticas adecuadas y un buen marco legal y, a la sociedad, toda tomar conciencia del valor de los ancianos como sujetos activos de la misma, promotores de cambio y portadores de valiosa sabiduría, tal como en algún momento de la historia de la humanidad se les reconoció.

117 Así lo sostiene STANZIONE (2007) pp. 63-64.

118 CiUro (1992) p. 39. 


\section{BIBLIOGRAFÍA CITADA}

AMORÓs, C. (1990): "Violencia contra las mujeres y pactos patriarcales", en: MAQUIEIRA, V. y SÁNCHEZ, C. (comp.): Violencia y Sociedad Patriarcal (Pablo Iglesias, Barcelona) pp. 1-15.

ARA Pinilla, I. (1990): Las transformaciones de los derechos humanos (Tecnos, Madrid).

ARCE FlÓREZ-VAldÉS, J. (2003): "La incapacidad eventual de autogobierno y las declaraciones de voluntades anticipadas (La tutela del siglo XIX)", en: Estudios Jurídicos en Homenaje al Profesor Díez-Picazo, Vol. I (Thomson Civitas, Madrid) pp. 207-220.

BobBio, N. (1997): De Senectute y otros escritos biográficos (Taurus, Madrid).

Brogden, M. (2001): Geronticide: killing the Elderly (Jessica Kingsley Londres), cit. por KInGSTON, P. (2005): "Una perspectiva histórica del maltrato institucional de personas mayores", en: IBORRA MARMOLEJO, I. (ed.): Violencia contra las personas mayores (Ariel, Barcelona) pp. 133-168.

CADOCHE, S. R. (2002): "Violencia familiar y ancianidad", en: CADOCHE, S. R. (directora): Violencia Familiar (Rubinzal-Culzoni, Buenos Aires) pp. 93-101.

Casado Marín, D. y López Y Casasnovas, G. (2001): Vellesa, depència i atencions de llarga durada. Situació actual y perspectivas de futur (Barcelona, Fundació La Caixa) pp. 208 y ss., cit. por ROCA TRIAS, E. (2003): "La autonomía personal, fundamento de la gestión de los intereses de la tercera edad en Cataluña", en: Estudios Jurídicos en Homenaje al Profesor Diez-Picazo, Vol. I (Thomson Civitas, Madrid) pp. 818-839.

Cepal (2007): Ni una más! El derecho a vivir una vida libre de violencia en América Latina y el Caribe, Informe Regional.

Chimeno CANo, M. (2005): "El ingreso forzoso de ancianos en centros especializados", Sentencias de TSJ y AP y otros Tribunales, Núm. 1/200, Parte Comentario, Editorial Aranzadi, Pamplona, pp. 9-15.

Cicerón, M. T. (2001): De senectute. Acerca de la vejez (Triacastela, Madrid).

Ciuro Caldani, M. (1994): "Comparación jusfilosófica del Derecho de menores y el Derecho de la ancianidad", Investigación y Docencia, No 25: pp. 7-11.

Ciuro Caldani, M. (1992): "Derecho de la ancianidad", Investigación y Docencia, Núm. 20, pp. 35-40.

Conseil De L'europe. Groupe D’étude Sur la Violence Envers Les Personnes ÂGÉES (1992): La violence envers les personnes âgées, Strasbourg.

DABOve, M. (2005/2006): "Discriminación y ancianidad. Reflexiones filosóficas en torno al sistema jurídico argentino", Revista Telemática de Filosofía del Derecho, Núm. 9, pp. 153-164.

Dabove, M. (2005): Los derechos de los ancianos (Ciudad Argentina, Buenos Aires).

DABOVE, M. (2005a): "Geriátricos en Argentina: complejo punto de encuentro del derecho público y privado", en: Alterini, A. (Dir.), Nicolau, N. (Dir), HernánDEZ, C. (Coord.): El Derecho Privado ante la internacionalidad, la integración y la globalización. Homenaje al Prof. Miguel Ángel CIURO CALDANI (Ed. La Ley, Buenos Aires) pp. 51-58. 
Dabove, M. (2000): "Derecho de la Ancianidad y Bioética en las instituciones geriátricas", en: Homenaje a Dalmacio Vélez Sarsfield, T. III, pp. 205-236.

Dabove, M. (2000a): "Razones Iusfilosóficas para la construcción de un Derecho de la Ancianidad", Jurisprudencia Argentina, No 4: pp. 1021-1027.

Drane, J. (2000): "Aging and dying: medical and ethical considerations", en Acta Bioethica, Año VII, No 1: pp. 97-106.

Enríquez Rosas, R. y Alderete González, A. (2003): “'Espacios a media luz'. Redes de apoyo social y adultos mayores en contextos urbanos de pobreza extrema en México: un estudio de caso", Simposio Viejos y Viejas Participación, Ciudadanía e Inclusión Social, 51 Congreso Internacional de Americanistas. Santiago de Chile 14 al 18 de julio de 2003.

Figueroa YÁÑEZ, G. (2007): "Algunas consideraciones acerca de la vida y de la muerte", VII Congreso Interamericano de Academias de Derecho y Ciencias Sociales de Iberoamérica-Memorias, Bogotá, Colombia, 14 al 17 de noviembre de 2007, pp. 335 y ss.

Frustagli, S. y HernÁNDEZ, C. (2005): "Algunas cuestiones contractuales y de daños derivadas de la prestación de servicios geriátricos", Revista de Responsabilidad Civil y de Seguros, No 3: pp. 79-92.

Galván Gallegos, Á. (2001): "La tutela respecto de la tercera edad", Actualidad Civil, Ref. XLIII, Tomo 3, Editorial La Ley: pp. 1025-1032.

Gujjarro Morales, A., Gujjarro Huertas, A., Gujjarro Huertas, G. (2001): El Sindrome de la Abuela Esclava. Pandemia del Siglo XXI (Grupo Editorial Universitario, Granada).

Hoebel, A. (2005): El hombre en el mundo primitivo, trad. Miguel Fusté, Barcelona, Omega, 1961, cit. por DABOVE, M., Los derechos de los ancianos (Ciudad Argentina, Buenos Aires) p. 122.

Instituto De Mayores Y Servicios Sociales (Imserso) (2007). Observatorio de las Personas Mayores, "Perfiles y tendencias", Boletín sobre el Envejecimiento, No 31: octubre.

Kemelmajer De Carlucci, A. (2006): "Las personas ancianas en la jurisprudencia argentina: ¿hacia un Derecho de la Ancianidad?”, Revista Chilena de Derecho, vol. 33, No 1: pp. 37-68.

Kingston, P. (2005): "Una perspectiva histórica del maltrato institucional de personas mayores", en: IBORRA MARMOLEJO, I. (ed.): Violencia contra las personas mayores (Ariel, Barcelona) pp. 133-168.

Instituto NaCiOnal De Estadísticas (INE) (1999): Chile y los adultos mayores, impacto en la sociedad del 2000.

Linacero De La Fuente, M. (2004): "Protección jurídica de las personas mayores", Actualidad Civil, No 19: quincena del 1 al 15 de noviembre, Tomo 2, Editorial La Ley: pp. 2262-2275.

LOLAS STEPKE, F. (2006): Escritos sobre vejez, envejecimiento y muerte (Ediciones Campus de la Universidad Arturo Prat, Iquique).

MANTHORPE, J. (2000): "El maltrato a los ancianos y las áreas prioritarias en el trabajo 
social”, en: DeCAlmer P. y GLendenning, F. (compiladores): El maltrato a las personas mayores (Paidós, México) pp. 119-135.

Medina, G. y et al. (1998): La Adopción (Rubinzal Culzoni, Buenos Aires), Tomo I.

Molina Linde, J., Molina Montes, E., Rodríguez Madrid, M., Uribe, A., (2008): "Una forma de esclavitud en pleno siglo XXI: el síndrome de la abuela esclava", Revista multidisciplinar de gerontología, Vol. 18, No 1: pp. 32-35.

Morcillo, S. (2004): "El desamparo legislativo de la ancianidad", Actualidad Jurídica de Córdoba. Familia y Minoridad, Vol. I: pp. 844-858.

Morelli, M. (1999): "Ética, Derecho y Ancianidad. Algunas cuestiones vinculadas con el concepto de ancianidad", Revista de Bioética y Bioderecho, No 4: pp. 33-40.

Muñoz Tortosa, J. (2004): "Protección jurídica de las personas mayores", en: MUÑOZ Tortosa, J., Personas mayores y malos tratos (Ediciones Pirámide, Madrid) pp. 171-171-187.

Outomuro, D. (2003): "Algunos dilemas bioéticos en torno a la vejez", Ars Medica, vol. 8 No 8 (en línea) [22 de julio de 2008]. Disponible en: [http://escuela. med. puc. cl/publ/arsmedica/ArsMedica8/Art05. html\#].

PECES-BARBA, G. (1988): Escritos sobre derechos fundamentales (Eudema, Madrid).

Pérez LuÑo, A. (2003): Derechos humanos, estado de derecho y constitución (Tecnos, Madrid).

RETUERTO BUADES, M. (2000): "Dimensión constitucional de la protección a la tercera edad", Actualidad Administrativa, ref. XXXI, Tomo 2, Editorial La Ley, pp. 597-611.

Rico, N. (1996): Violencia de Género: Un problema de Derechos Humanos, CEPAL. Serie Mujer y Desarrollo, No 16.

Rivero, M. R. (2002): "Maltrato hacia los ancianos", en: CADOCHE, S. R. (directora): Violencia Familiar (Rubinzal-Culzoni, Buenos Aires) pp. 291-306.

RoCA TRIAS, E. (2003): "La autonomía personal, fundamento de la gestión de los intereses de la tercera edad en Cataluña”, en: Estudios Jurídicos en Homenaje al Profesor Diez-Picazo, Vol. I (Thomson Civitas, Madrid) pp. 818-839.

RUBiO, R. (2005): "Concepto, tipos, incidencia y factores de riesgo del maltrato institucional de personas mayores", en: IBORRA MARMOlejo, I. (ed.): Violencia contra las personas mayores (Ariel, Barcelona) pp. 101-115.

Sagrega, M. (1992): El edadismo. Contra "jóvenes" y "viejos". La discriminación universal (Fundamentos, Madrid).

Servicio Nacional Del Adulto Mayor (SENAMA) (2008): Estudio Actualización de Registros para Establecimientos de Larga Estadia para Adultos Mayores en Chile.

Servicio Nacional Del Adulto Mayor (SENAMA) (2007): Estudio de Situación de los AM dependientes con pensión asistencial y sus cuidadores domiciliarios.

Servicio Nacional Del Adulto Mayor (SENAMA) (2007a): Guia de Prevención del Maltrato en Personas Mayores.

SierRa Gil De La CUeSTA, I. (2001): "Las personas mayores en el ámbito del derecho civil”, en: GonzÁlez Porras, J. y Gallego Domínguez, I. (coord.): Problemas legales sobre la tutela, asistencia y protección de las personas mayores, Actas de las Primeras Jornadas de problemas legales sobre tutela, asistencia y protección a las personas 
mayores: Córdoba, 17-18 de noviembre de 2000, Obra Social y Cultural Cajasur, pp. 87-94.

STANZiOne, P. (2007): "Personas mayores, capacidad y tutela jurídica: la situación italiana”, en: LASARTE ÁlvAREZ, C. (director): La protección jurídica de las personas mayores (Tecnos, Madrid) pp. 50-70.

Tomasello, A. (2002): "Derechos de la ancianidad", Doctrina Judicial 3, pp. 928-941.

Trejo Maturana, C. (2001): "El viejo en la historia", Acta Bioethica, Año VII, No 1: pp. 109-110.

VASAK, K. (1977): "La larga lucha por los derechos humanos", El Correo de la Unesco, Vol. XXX, pp. 28-32.

VIVANCO MARTíneZ, A. (2003): "Los derechos de los ancianos: las paradojas bioéticas de la ancianidad en la perspectiva de los derechos de tercera generación", Ars médica, No 8: pp. 189-213.

Wilde, Z. (2003): "El valor de la autonomía de la voluntad frente a la vejez o a la circunstancia de caer en incapacidad", Revista del Notariado, Vol. 106, No 873: pp. 127-130.

Zambrano V. (2007): "La protección de los mayores entre el Código Civil y la ley especial. La experiencia italiana”, en: LASARTE ÁlVAREZ, C. (director): La protección jurídica de las personas mayores (Tecnos, Madrid) pp. 71-96.

\section{WORLD WIDE WEB}

[http://www.ine.cl/canales/chile_estadistico/estadisticas_sociales_culturales/adultosmayores/pdf/cifrasmayores.pdf] [fecha de consulta: 22 de julio de 2008]

[http://www.ine.cl/canales/elemento_persistente/preguntas_frecuentes/ preguntas_frecuentes. php] [fecha de consulta: 22 de julio de 2008]

[http://www. globalaging. org/elderrights/world/2005/maltrato.htm.] [fecha de consulta: 22 de julio de 2008]

[http://www.memoriachilena.cl/temas/index.asp?id_ut=lacuestionsocialenchile18801920] [fecha de consulta: 22 de julio de 2008]. 
